\title{
iGREEN: An Integrated Emission Model for Mixed Bus Fleets
}

\author{
Maria Vittoria Corazza ${ }^{1, *(D)}$, Paulo Cantillano Lizana ${ }^{2}$ (D) Marco Pascucci ${ }^{3}$, Enrico Petracci ${ }^{2}$ and Daniela Vasari $^{2}$ \\ 1 School of Engineering, Department of Civil, Building and Environmental Engineering, \\ Sapienza University of Rome, 00184 Rome, Italy \\ 2 PLUSERVICEs srl, 60019 Senigallia, Italy; p.cantillano@pluservice.net (P.C.L.); e.petracci@pluservice.net (E.P.); \\ d.vasari@pluservice.net (D.V.) \\ 3 Pascucci Consulting, 00196 Rome, Italy; mp@ingmarcopascucci.it \\ * Correspondence: mariavittoria.corazza@uniroma1.it; Tel.: +39-06-4458-5718
}

Citation: Corazza, M.V.; Lizana, P.C.; Pascucci, M.; Petracci, E.; Vasari, D. iGREEN: An Integrated Emission Model for Mixed Bus Fleets. Energies 2021, 14, 1521. https://doi.org/ $10.3390 /$ en14061521

Academic Editor: Sergio Ulgiati

Received: 9 February 2021

Accepted: 8 March 2021

Published: 10 March 2021

Publisher's Note: MDPI stays neutral with regard to jurisdictional claims in published maps and institutional affiliations.

\begin{abstract}
The environmental concern has become central for many bus companies, but estimating pollutant emissions can be difficult for many reasons (little knowledge or underestimation of the problem; scarce know-how; reluctance to acknowledge the pollutant potential of bus fleets because either of small size or composed by too many old-generation vehicles). To facilitate this task, an integrated, user-friendly model, $i G R E E N$, is presented. The paper describes the methodology for the development of this tool, which is specifically designed to help transit operators in assessing the pollutants emitted by fleets where the amount of old buses is not negligible. This is not a minor issue, given the large number of obsolete vehicles still circulating and the unsuitability of some models when calculating emissions in case of buses with protracted mileage. Results from two case studies are reported and commented, with the final aim to advance knowledge farther afield. This gives rise to a discussion on the relevance of such environmental concerns also in light of the contemporary pandemic which seem to have generated different priorities in the public transport management.
\end{abstract}

Keywords: air pollutants; emissions; buses

\section{Introduction}

Since the beginning of the 21st century the environmental concern has become imperative in the automotive sector, with passenger cars having the lion's share both in the clean-vehicle market segment and in the public perception of the problem.

However, for public transport companies the "green" option is equally important, as operations often rely on old vehicles. The 2019 UITP survey outcomes provide some relevant facts and figures: about one in three buses in the world is still pre EURO IV, and just around $15 \%$ of the surveyed fleets are composed by EURO VI buses. Additionally, although the average age of the vehicles might seem young (6.9 years), this is partly due to significant concentrations of newer vehicles in large countries such as Brazil, China, Indonesia, and Russia. In terms of propulsion, conventional fuels are still dominant $(67.4 \%$, including both diesel and diesel plus additives options), compared to biodiesel, CNG and LPG $(15.4 \%$ ), and electricity (up to $17.2 \%$, including pure electric, hybrid and electric battery-powered vehicles) [1].

At supranational level, the willingness to boost eco-friendlier operations within urban transit is getting stronger and stronger and electrification is expected to escalate, being to date the leading segment in the overall electric vehicles market, with the electric share reaching $67 \%$ of the global bus fleet in 2040. By the same horizon, fuel cell applications are forecast to account for $6.5 \%$ of bus yearly sales [2]. As to Europe, the transition towards cleaner buses and electrification is in progress, also thanks to the European Commission funds, specifically allocated to advance the Research and Innovation field towards the creation of the Bus of the Future [3,4].

However, in spite of such genuine willingness to change, too many old and polluting buses are operating in many urban areas and Italy is a case in point: more than $70 \%$ of the 
urban buses are diesel-fueled, with 11 years as average age, which accounts for $51 \%$ of pre-EURO-V-compliant vehicles [5]. The reasons to explain the phenomenon are many as the conversion to cleaner fleets is affected by many factors.

At a decision-making level, the process is usually politically driven which implies a local or national commitment, which in turn is affected by the availability of funding and by the magnitude of the fleet to convert. Both issues involve limitations. In the case of funding, these are usually based on limited and/or one-off subsidizing programs. Examples worldwide are many: the US "Low or No Emission Competitive Program" granted funds to public transit authorities to purchase cleaner vehicles over the 2016-2020 period; same end for the Chinese "Ten Cities, Thousand Vehicles" program which lasted 10 years and ended in 2020; the British "Investing in ultra-low emission vehicles in the UK 2015 to 2020 " statement gave rise to the 2015-2018 "Ultra-low emission bus scheme" grant. The availability of funding is of the utmost importance due to the higher investment costs associated with alternatively fueled buses if compared to diesel ones, even though the lower maintenance expenditure for the former has been remarked [6].

The fleet size might turn in an additional hindrance due to the understandable operators' reluctance to manage more technologies within the same garage. In case of large fleets this might require additional facilities (for example, in London the Waterloo garage operates electric-only, with 43 charging points). For smaller fleets this would equate also to the introduction of new know-how, with additional costs, more staff.

This means that innovation and especially electrification calls for large scale to be cost-effective within a near horizon $[3,6]$ due to the relevant infrastructural investments and advanced technological solutions [7]. Yet, the feasibility of a full replacement of a conventional fleet with an electric-only one is in dispute [8].

Last to consider is the higher cost, per se, of nondiesel vehicles if compared to the conventional ones: this implies that the amount of conventional buses that can be purchased is higher than that of innovative vehicles, being given an equal subsidy. The consequences are clear and Italy can be again a case in point. A recent funding program is specifically designed to steer the transition towards cleaner bus fleets over an 8-year period, with EUR 2.5 billion allotted yearly to purchase nondiesel vehicles. Forecasts of a consequent smaller amount of new, nonconventional buses into operations will imply that the average age of vehicles, at national level, will raise from 11 to 17.5 years in 2033 [5].

Thus, the eco-conversion of bus fleets can be an efficient practice to abate exhaust emissions, although demanding and not always fully viable [8]. In this case, operators have to try to mitigate the phenomenon with their own resources, i.e., with the fleets they operate. To do this, they have to be aware of the amount of pollutants their fleets generate: but in the case of small fleets, a problem could be the operators' underestimation of the environmental consequences due to the restricted amount of buses they manage, even when the share of old vehicles is not negligible. Likewise, in metropolitan areas, the problem of underestimating the buses' emissions is recurring too, as the transit emission package is generally considered secondary to those generated by passenger cars and commercial fleets. A reliable evaluation of traffic emissions generated by all the transport modes is essential for the development of sustainable mobility policies, as also demonstrated by the transit operators' intention to innovate [9] and operate more nonconventionally fueled modes [3,4].

This introduces the problem of emission modeling, which is common not only for road transport (and transit in the present case), but also for air and maritime operations. It was observed that, in scientific literature, studies with the application of energy-based models in usual planning problems, like that of vehicle routing were still not many, and the integration of environmental factors, namely GHG emissions, was lagging behind. To fill the gap, an interesting approach is provided by the Pollution-Routing Problem study, where the reduction of energy required of vehicle routing is carried out including a comprehensive emissions model [10]. Maritime operational strategies also experience emissions problems, as highlighted in [11], and studies aimed at solving optimization recurring topics like 
the Berth Allocation Problem [12] or the mode choice and shipment planning [13] have been reformulated to include also fuel consumption and emissions. The same approach is followed in air transport, where the development of optimization models is targeted to include the emission problems, also to comply with more stringent regulations like the European Union Emissions Trading Scheme [14].

Moving from these problems, the position of many public transport companies can be difficult: although wishing to operate in an environmentally conscious way, they have to manage fleets with mixed EURO-engines, with a not negligible amount of obsolescing vehicles and for which a total renewal can be demanding. At the same time, modeling emissions can be a process that many operators are not fully familiar with, as elaborated in Section 2.

\section{Rationale of the Paper}

Coherently with all of the above, the research question is how to help transit operators to go "green" with the current resources, prior to prospective massive adaptation. The proposed solution is to control the exhaust emissions produced by the mix of EURO-engines fleets they manage, via a specific methodology specifically conceived to develop iGREEN (an inteGRatEd EmissioN model) to assess emissions from different types of buses, including those pre-EURO V. The research goal is to provide a reliable estimation of emissions and enable operators to be aware of the pollution packages older vehicles emit and adapt operations accordingly. The innovative features of $i$ GREEN are fully described as well as its difference with other emission models (Section 2); the developed methodology (Section 3) and its application in two different case studies in Italy, in the cities of Olbia and Cuneo are reported (Section 4). Results are presented (Section 5) and commented (Section 6), along with some concluding remarks (Section 7), with the final aim to advance knowledge farther afield.

\section{The Right Emission Model for the Right Bus Fleet}

As introduced, in scientific literature models to estimate traffic emissions abound, even though most of the case studies focusing on buses were developed during the first decade of the 2000s. This can be explained by the observation that this is the period when, in Europe, the majority of EURO-standard fleets were deployed, with the EURO VI enforced later by the EC 595/2009 Regulation. Likewise, in the US, regulations for heavy-duty engines' emissions enforced a similar standard (US2010) between 2013 and 2014 [15]. More recent case studies are also available, mostly addressing performance comparisons among fleets composed, however, by a majority of new buses [16-18].

Limitations in the models, typically the difficulties in describing the drivers' behaviors, can be compensated by tests in lab or real environments, either via driving cycles trials or the possibility to test Real-Driving Emissions (RDEs) by Portable Emissions Measurement Systems (PEMS). PEMS, developed since the 1990s, are now compulsory in Europe when testing RDEs, for example, for light-duty vehicles [19]. Yet, PEMS' overall accuracy can be disputed [20]. As for emission models, a large number of case studies on PEMS is available in literature, mostly focused on large metropolitan areas [21-23] or on higher capacity vehicles [24], yet the introduction of new technologies and their continuous advances call for further investigations $[25,26]$.

Therefore, the ideal condition for operators would be to collect information on bus emissions from simulations, test-bench activities in general and PEMS. However, PEMS can be inconvenient as the equipment needs to be installed on every kind of vehicle included in the test program, a demanding task in case of fleets composed by vehicles with different Euro-compliant engines, aside from the problem of the operational stop due to installation.

\subsection{Emission Models: Features and Difficulties}

This seems to leave emissions modeling as a more viable option. However, along with the time-consuming data process and demanding results interpretation, the very selection 
of the model calls for specific knowledge. The technological advances in terms of propulsion systems, fuels, lubricants and specific engines performance were enabled through the years the development of several emission models and different emission inventories (and related software). Moreover, in Europe, an additional support has been provided by several research projects funded by the European Commission in the field of sustainable urban mobility (especially within the CIVITAS Initiative), where the emissions assessment was central in the overall evaluation of impacts of the policies and measures under test, and for which models were largely used. Consequently, today several methodologies are available to meet specific requirements in terms of accuracy and scale, encompassing a variety of inputs associated with different operations, vehicle and emission profiles $[27,28]$.

Within such availability, the choice might be difficult just because of such abundance of options, as summarized in [29]. In fact, a univocal taxonomy of models is difficult to build. These can be subdivided according to inputs, i.e., scale (from macroscopic at regional level, to microscopic concerning specific links and nodes in the road network [30,31]); mode, traffic situation, or performance considered [32,33], which give rise to the Modal Models group; according to fuel used [34]; moreover, emission models can be subdivided according to data process (aggregated or disaggregated emission factor models; multiple linear regression models, etc.). Each group is associated with specific emission inventories [17,35], which have become more and more accurate and reliable through the years, to render simulations as close as possible to real operations.

In this process, the possibility to rely on a supranational reference, among the many models available, can be considered an achievement because of the possibility of having a single acknowledged tool and a single data process associated with a specific inventory, and able to provide comparable results. This is the case of COPERT, the standard, softwarebased method to simulate emissions from road transport in Europe, developed under the coordination of the European Environmental Agency-EEA and largely adopted in virtually all European countries. COPERT features are also compatible with non-European fleets, with many applications documented, among these [17,36-39].

COPERT can be defined an "average speed model" within the larger modal models group, according to the definitions in [32,33], as it relies on average emission factors for each pollutant considered and given type of vehicle variation according to the vehicle's average speed, as inputs. Until its ultimate 2019 version, currently available, COPERT has increased the quality and quantity of data to process, by including a very large amount of pollutants (considering both the regulated ones, i.e., $\mathrm{CO}, \mathrm{NO}_{\mathrm{x}}, \mathrm{VOC}$, particulates and the unregulated ones, like $\mathrm{N}_{2} \mathrm{O}, \mathrm{NH}_{3}, \mathrm{SO}_{2}, \mathrm{NMVOC}$ ) to estimate hot, cold-start and nonexhaust emissions for a vast array of vehicles (passenger cars, light and heavy duty vehicles including buses, and powered two-wheelers-PTWs), and propulsions.

The basic inputs are environmental and emission factors, types of engines, fuel specifications. For each vehicle, the emission factors outline the performance profile according to kinematics (speed, acceleration and deceleration), local conditions (weather, elevation of the roads, etc.) and behavior (different driving cycles) [38] for which the "package" of emitted pollutants is calculated. In addition, one more important parameter is the age of the vehicle, in the assumption that older vehicles with protracted mileage pollute more, which gives rise to the "Mileage degradation" factor. This factor is used to associate the vehicle age or annual driven mileage with an additional, consequent emission degradation factor.

The mileage degradation factor is crucial: for EURO I and EURO II passenger cars, with mileage higher than $80,000 \mathrm{~km}, 60 \%$ increase in the emissions of $\mathrm{CO}$ and $\mathrm{NO}_{\mathrm{x}}$, and $30 \%$ more in the NMVOC can be observed [39].

Although more and more comprehensive, COPERT does not enable to compute the mileage degradation factor specifically for diesel buses. For example, the calculation of the amount of a $\mathrm{CO}_{2}$ emitted by a EURO III bus, even with a modest average mileage of 50,000 km per year, renders the constant, but improbable, trend reported in Figure 1, if simulated over an 8-year operational timespan. 


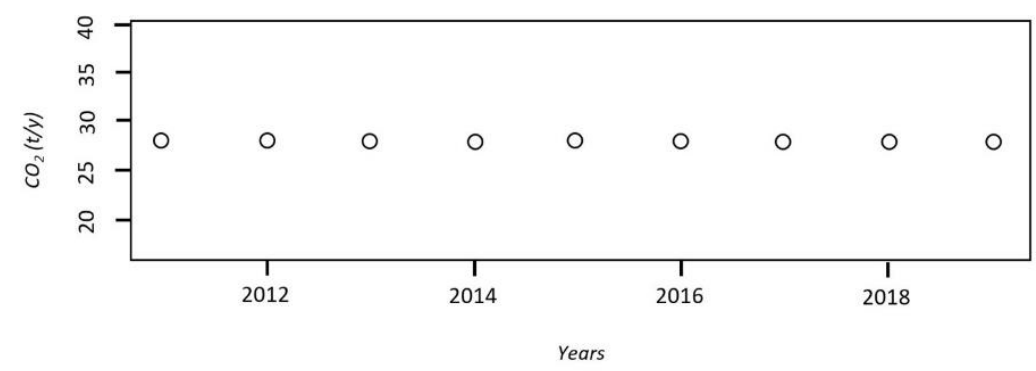

Figure 1. COPERT simulation of the $\mathrm{CO}_{2}$ emissions by a EURO III bus with a $400,000-\mathrm{km}$ mileage.

The Problem of Obsolescence

Figure 1 also provides the basis for two considerations. The first is that there is no "universal" model; the different models and related software currently available all have limitations, like the one just mentioned for COPERT and noted in literature [32,33,40], which call for adaptation when transferred to operational scenarios different from the ones they were conceived for [35]. The second consideration is about the approach in the models' design: by including more and more types of vehicles, propulsion systems, fuels and lubricants in the inventories, designers enlarge the models' inputs quantity and quality for the sake of accuracy and reliability. However, this approach is naturally oriented towards a turnover of the fleets, with an expected constant renewal with newer, cleaner and more efficient vehicles, and minor attention to "obsolescence" (e.g., vehicles' age, protracted mileage, lubricants' degradation, etc.).

The lesson learnt is, however, of stagnation periods where turnovers are slower. Results from the 2013 "Survey on Energy Efficiency" are an example. This survey, developed within the project "EBSF-The European Bus System of the Future" funded by the European Commission [4], was designed to outline recurring problems among public transport operators concerning environmental requirements and energy efficiency. Respondents from 34 European transit companies "represented" a total annual production of more than 2 billion vkm. The resulting snapshot was a full picture of the situation of the European fleets at that time, with a composition divided into about 30\% EURO I and EURO IIcompliant vehicles, 30\% EURO III-compliant ones, and just a little more than $30 \%$ including EURO IV and EURO V or enhanced environmentally friendly vehicles (EURO VI standards were enforced later). The obsolescence of the fleets was behind the general intention to renovate them, yet $20 \%$ of the respondents were still oriented towards retrofitting or less specific actions. Moreover, according to the respondents it was clear that two generations of vehicles (the EURO IV and EURO V compliant ones) could not have a full deployment, due to prolonged service of EURO III vehicles [4,41].

Not much has changed nowadays, considering that the variation in the registrations of new buses and coaches between 2018 and 2019, across the 28 European Union Member States, is just $+0.5 \%$, with an average of 45,500 new vehicles registered yearly [42] This means that fleets' obsolescence is definitely a recurring issue, although not much addressed, and that in terms of emissions estimation, leaving aside specific parameters to compute its effects leads to an underestimation of the problem.

\section{A Methodology to Address the Obsolescence Issue}

In Europe, the reply to the research question, i.e., how to manage bus fleets with still too many poor performing vehicles under the environmental point of view, in the absence of fast fleets renewal, can be found in the possibility to control emissions and adapt operations accordingly. This raises one more issue, that of properly computing the mileage degradation, when COPERT is to be used as a reference model. Again, resorting to other models could be difficult, especially in case of different inventories.

A specific methodology was, thus, designed and adopted to integrate COPERT with other models and tested in two Italian case studies, two middle-size towns further described. The study was prompted by the national funding program mentioned in Section 1, 
in the awareness that some transit companies, for which a total conversion of their fleets would not be affordable, are expected to manage buses with a longer operational life.

The resulting model, iGREEN, was embedded in a specific software, developed during the EBSF_2 project (a follow-up of the above-mentioned EBSF project), still funded by the European Commission [4]. This software was initially designed to manage predictive maintenance operations at bus garages [43]. The iGREEN new features to embed were thus specifically designed to improve the quality of the maintenance diagnostics, by providing additional predictive information on the emissions.

\subsection{The iGREEN Development}

In order to cope with the issues to operate old vehicles with protracted mileage, relying on COPERT as the more common tool to simulate emissions in Europe, although not specifically suitable to process data for such vehicles, the research was steered towards the study of its integration with other models. The leading criteria were (i) the possibility to include among the inputs the mileage degradation for bus fleets, with values higher than $80,000 \mathrm{~km}$; (ii) the compatibility with Euro standards; (iii) the feasibility to merge or integrate different data processes. The final selection left the International Vehicle Emissions (IVE) model, as the most viable solution for a fruitful integration with COPERT.

IVE, which has been largely described elsewhere [44-46], can be associated with the Modal Models group, and thus is compatible with COPERT. Even though it was initially conceived in the U.S. for developing countries, IVE has been actually implemented in a number of case studies worldwide [47-49]. IVE relies on three components: vehicle emission rates; vehicle activity, and the fleet distribution. Among the inputs, the vehicle technology distribution (with 1372 predefined technologies), air conditioning performance, fuel and injection types, and the emission factor adjustment by technology and pollutant are available. More important for the case in hand, IVE enables the emissions calculation for buses according to three mileage classes, $M_{n}$, i.e.,

- $M_{1} \leq 80,000 \mathrm{~km}$;

- $80,000 \mathrm{~km} \leq M_{2} \leq 161,000 \mathrm{~km}$;

- $M_{3}>161,000 \mathrm{~km}$, thus coping with the COPERT's limitation.

Lastly, IVE is able to calculate the daily amount of pollutants per hour, according to the driving behaviors (i.e., analyzing speed, acceleration and deceleration) which affect emissions in function of the engine power and its levels of performance and stress. The previous attributes are useful to calculate two supplementary parameters in IVE: Vehicle Specific Power (VSP), and Engine Stress (ES), further elaborated in Section 3.2.2. The possibility to include driving conditions is not negligible, not only because this can cope with the common limitation of some models to include that (as highlighted in Section 2), but also because carbon oxide emissions can increase up to 200 times under given driving conditions [50].

As remarked, there is no universal model, and IVE can have some disadvantages too, for three reasons: (i) in case of very small-scale operations, the three mileage classes might be too vast; (ii) the need of GPS devices to collect data; (iii) it does not include EURO VI performance and the lubricants among the inputs, both on the contrary fully processed by COPERT. However, a comparison between the two models is provided in Table 1.

Thus, the integration of the two models into iGREEN provides two major opportunities. From the research side, relying both on IVE to contemplate cases with very high mileage (more than 161,000 km), and on COPERT to include EURO VI performance, enables to develop a more comprehensive calculation procedure. Under the practical point of view, transit operators, who usually have no resources to process different models according to the specific requirements of the vehicles they manage, can rely on a single, simple procedure to easily calculate emissions. 
Table 1. Qualitative comparison between COPERT and IVE.

\begin{tabular}{|c|c|c|}
\hline & COPERT & IVE \\
\hline \multicolumn{3}{|c|}{ Input Variables } \\
\hline $\begin{array}{l}\text { Environmental } \\
\text { information }\end{array}$ & $\begin{array}{l}\text { Annual average minimum and maximum } \\
\text { temperature }\left(\mathrm{C}^{\circ}\right) \text {, humidity }(\%)\end{array}$ & Altitude (m) \\
\hline Fuel specifications & $\begin{array}{l}\text { Energy content }(\mathrm{MJ} / \mathrm{kg}), \mathrm{H}: \mathrm{C} \text { ratio, } \mathrm{O}: \mathrm{C} \text { ratio, } \\
\text { Density, } \mathrm{S}, \mathrm{Pb}, \mathrm{Cd}, \mathrm{Cu}, \mathrm{Cr}, \mathrm{Ni}, \mathrm{Se}, \mathrm{Zn}, \mathrm{Hg} \text {, As }\end{array}$ & $\begin{array}{l}\text { Gasoline (fuel quality, S, Pb, Benzene, \% Oxygenate), } \\
\text { diesel (fuel quality, S) }\end{array}$ \\
\hline Lubricant specifications & $\begin{array}{c}\mathrm{S}, \mathrm{Pb}, \mathrm{Cd}, \mathrm{Cu}, \mathrm{Cr}, \mathrm{Ni}, \mathrm{Se}, \mathrm{Zn}, \mathrm{Hg}, \mathrm{As}, \mathrm{H}: \mathrm{C} \text { ratio, } \\
\text { O:C ratio }\end{array}$ & No specifications \\
\hline Stock configuration & $\begin{array}{c}448 \text { different vehicles with different } \\
\text { technologies available }\end{array}$ & $\begin{array}{c}1372 \text { different vehicles with different } \\
\text { technologies available }\end{array}$ \\
\hline $\begin{array}{l}\text { Stock data per vehicle } \\
\text { per technology }\end{array}$ & $\begin{array}{l}\text { Annual mean activity }(\mathrm{km}) ; \text { lifetime cumulative } \\
\text { activity }(\mathrm{km})\end{array}$ & $\begin{array}{l}\text { Distance }(\mathrm{km}) \text { and average speed }(\mathrm{km} / \mathrm{h}) \text { in the hour } \\
\text { evaluated. Acceleration, deceleration and grade of } \\
\text { slope, second-by-second }\end{array}$ \\
\hline $\begin{array}{l}\text { Circulation mode } \\
\text { per vehicle, } \\
\text { technology }\end{array}$ & $\begin{array}{c}\text { Emission factors defined by \% in rural, urban or } \\
\text { highway and their average speed in each } \\
\text { mode }(\mathrm{km} / \mathrm{h})\end{array}$ & $\begin{array}{l}\text { Emission factors using the VSP and engine stress } \\
\text { calculated by the user and the table of BINs }\end{array}$ \\
\hline Emission calculation method & Vehicle activity $\times$ emission factor & $\begin{array}{l}\text { Vehicle activity disaggregated by specific } \\
\text { mode } \times \text { emission factor }\end{array}$ \\
\hline \multicolumn{3}{|c|}{ Outputs } \\
\hline $\begin{array}{l}\text { Types of emissions } \\
\text { Estimated pollutant packages } \\
\text { Default output units }\end{array}$ & $\begin{array}{c}\text { Hot and cold emissions } \\
25 \text { pollutants, including GHG }\left(\mathrm{CO}_{2}, \mathrm{CH}_{4}, \mathrm{~N}_{2} \mathrm{O}\right) \\
\text { tons/year }\end{array}$ & $\begin{array}{c}\text { Running and start-up } \\
15 \text { pollutants, including } \mathrm{GHG}\left(\mathrm{CO}_{2}, \mathrm{CH}_{4}, \mathrm{~N}_{2} \mathrm{O}\right) \\
\mathrm{kg} / \mathrm{h} ; \mathrm{kg} / \text { day }\end{array}$ \\
\hline \multicolumn{3}{|c|}{ Advantages and Disadvantages } \\
\hline Advantages & $\begin{array}{c}\text { Few input data to get a detailed emission calculation } \\
\text { Input information on kilometers travelled and } \\
\text { average speed is relatively easy to obtain from } \\
\text { traffic models or field measurements. } \\
\text { Large list of exhaust and nonexhaust pollutants } \\
\text { Large amount of data from the driving conditions } \\
\text { not needed }\end{array}$ & $\begin{array}{c}\text { It has a large library of vehicles and technologies } \\
\text { Emission factors are differentiated for various traffic } \\
\text { conditions and driving patterns (VSP and BIN, } \\
\text { further elaborated) } \\
\text { It can get a detailed behavior of the emission during a } \\
\text { single run }\end{array}$ \\
\hline Disadvantages & $\begin{array}{l}\text { Mileage degradation is not available for all the } \\
\text { vehicles and all technologies }\end{array}$ & $\begin{array}{l}\text { It does not consider the effect of the lubricant } \\
\text { Data may not be easy to get without GPS } \\
\text { It does not include Euro VI standard }\end{array}$ \\
\hline
\end{tabular}

The methodology, to develop this new integrated model, iGREEN (described in the next subsection), was therefore oriented to create a simplified tool, applicable to a vast range of operational scenarios with a special focus on those where the amount of old, polluting vehicles is not negligible.

\subsection{The Adopted Methodology}

The initial concept for this methodology was originated in a study to assess emission savings for car sharing operations in Rome [51]. When it was redesigned to estimate the emission packages for the local PTWs fleet, within two studies to acknowledge social costs due to poor safety and maintenance levels [52,53], the vehicles' obsolescence and protracted mileage became critical parameters in the assessment. Although the latter was not disseminated, the lesson learnt showed similarities between the PTWs and bus fleets: the need to integrate more models to describe in a more accurate way the emission phenomena, its underestimation, the relevance of maintenance to mitigate it. One more case study in Ravenna (norther Italy), based on preliminary COPERT-based calculations for a large set of pollutants emitted by a restricted fleet of buses under test within the above mentioned EBSF_2 project corroborated such lesson [43].

The methodology was to develop $i G R E E N$ from this approach, given the mutual set of problems between the two modes. The development of $i G R E E N$, however, required the perusal of the vast literature available after the initial study on PTWs, which led to an updated concept, capitalizing on most of the sources thus far cited and also on [54-56].

Coherently, $i G R E E N$ was developed to meet several requirements: scientific soundness; reliability; smooth embedment in the software for garage maintenance introduced at the beginning of Section 3; user-friendliness, to enable operators to easily assess the 
emission packages; comprehensiveness and, more important, flexibility and comprehensiveness to make it usable for the largest possible arrays of mixed bus fleets operating in Italy, and elsewhere.

Designed to take the most from both IVE (possibility to model performance with larger mileage) and COPERT (possibility to include the last available standard, EURO VI engines), iGREEN features are synthesized in Table 2.

Table 2. iGREEN features.

\begin{tabular}{|c|c|}
\hline \multicolumn{2}{|r|}{ iGREEN } \\
\hline \multicolumn{2}{|r|}{ Input Variables } \\
\hline $\begin{array}{l}\text { Environmental } \\
\text { information }\end{array}$ & $\begin{array}{c}\text { Three different average and significant temperatures }\left(20,25 \text { and } 30{ }^{\circ} \mathrm{C}\right) \text {, these could be } \\
\text { adaptable to the users' requirement, i.e., season average, monthly average, yearly } \\
\text { average; different types of slope }\end{array}$ \\
\hline Fuel specifications & Gasoline (fuel quality, S, Pb, Benzene, \% Oxygenate), diesel (fuel quality, S) \\
\hline Lubricant specifications & No specifications \\
\hline Stock configuration & Vehicles compliant with EURO standards from II to VI \\
\hline Stock data per vehicle per technology & Annual mean activity $(\mathrm{km})$; mileage $(\mathrm{km})$ \\
\hline $\begin{array}{l}\text { Circulation mode per vehicle, } \\
\text { technology }\end{array}$ & $\begin{array}{l}\text { Emission factors defined by operations in urban (long or short) or extra urban cycles, } \\
\text { with a large set of variables describing speed }(\mathrm{km} / \mathrm{h}) \text { and amount of engine ignitions } \\
\text { (events } / \mathrm{h})\end{array}$ \\
\hline Emission calculation method & Vehicle activity $\times$ emission factor (given by temperature, road slope and mileage) \\
\hline \multicolumn{2}{|r|}{ Outputs } \\
\hline Types of emissions & Running and start-up \\
\hline Estimated pollutant package & $\mathrm{CO}_{2}, \mathrm{NOx}, \mathrm{CO}, \mathrm{PM}, \mathrm{SOx}, \mathrm{NH}_{3}$ \\
\hline Default output units & tons/year \\
\hline \multicolumn{2}{|r|}{ Advantages and Disadvantages } \\
\hline Advantages & $\begin{array}{c}\text { Few and simple input data to get a detailed emission calculation } \\
\text { Fit to be easily used by EURO standard bus fleets } \\
\text { It considers the mileage information, or the age of the vehicles measured in km } \\
\text { Outcomes clearly revealing pollution levels }\end{array}$ \\
\hline Disadvantages & $\begin{array}{l}\text { Limited to the EURO technology } \\
\text { It does not consider temperature higher than } 30^{\circ} \mathrm{C}\end{array}$ \\
\hline
\end{tabular}

From the comparison among IVE, COPERT and iGREEN (Tables 1 and 2), for the latter elements of strength are clear:

- in terms of stock configuration, iGREEN specifically deals with vehicles compliant with EURO standards, from II to VI. This facilitates operators when selecting this option; on the contrary, in the other models, the same task could be time-consuming, as operators have to identify the right stock configuration among large sets of vehicles with different technologies;

- even fewer input data than COPERT and much less than IVE to get a detailed calculation of emissions;

- $\quad$ GGREEN's environmental variables are set to meet operators' different requirements (assessment according to season, monthly or yearly basis) and operational situations (different types of slopes), whereas the other models rely just on average minimum and maximum temperature and humidity (COPERT), or altitude (IVE);

- Emissions are, therefore, calculated according to a larger set of operational features (being computed the temperatures, slopes and mileage), than in the other models. 
Taking all these advantages into account, iGREEN is very appropriate not just when mileage degradation is a clear characteristic of the fleet in hand, but also whenever operational conditions are affected by a variety of driving environments and weather situations. The methodological process was multistep, as it included:

- Design of an initial emission inventory database for EURO IV and EURO V engines based on the IVE one and its further integration with the COPERT's one to include also inputs from buses with EURO VI engines. This resulted in the full iGREEN Emission Inventory Database (GEID);

- Development of bilinear regression functions to enable simplified calculations procedures (by a simple spreadsheet), from which the iGREEN algorithms for the maintenance software could be further implemented;

- Design of test features and selection of the case studies;

- Assessment of the case studies results for further refinement of the iGREEN procedures, if need be.

The most demanding tasks were the development of GEID, due to the amount of data to merge, and the calculation procedure. The latter was conceived to be time-saving for the operators, who just have to enter a limited amount of inputs, which in turn determine the right emission database to use for a given item (in the rows) in the model spreadsheet; each row and column are associated with a bilinear regression function and the algorithm corresponding to the mileage class. Each assessed pollutant relies on a different emission database.

More specifically, the calculation procedure was based on a first compilation of basic emission packages, developed for mixed EURO-compliant vehicles. The initial reference fleet was the one operational in the first of the two case studies included in the study (fully described in Section 4), due to its variety of vehicles, which enabled to identify the basic variables and their possible ranges of variation. This first step was developed through IVE and gave rise to a first set of databases (an example of which is reported in Table 3), which in turn allowed the identification of a corresponding set of simplified bilinear functions, with a special focus on EURO IV and V, as main type of vehicles in the case study.

The bilinear functions were calculated according to the following equations for any given $p$ pollutant in the pollutant package reported in Table 2, with exception of PM:

$$
\left\{\begin{array}{c}
\text { emissions }_{p}=m \cdot \text { mileage }+n, 0 \leq \text { mileage } \leq 80,000 \mathrm{~km} \\
\text { emissions }_{p}=\text { emissions }_{p, \text { max }}, \text { mileage }>80,000 \mathrm{~km}
\end{array}\right.
$$

where emissions $s_{\text {,max }}$ is calculated as maximum value between emissions at 80,000 and $160,000 \mathrm{~km}$, respectively. A minimal variation between these two mileage values was observed for all the pollutants, aside that for PM. Parameters $m$ and $n$ were the results of a linear interpolation between 0 and 80,000 km. Emissions at 80,000 km were always assumed as emissions $s_{p, \max }$, to avoid introducing discontinuity (even a minimal one).

PM emissions were similarly calculated as follows:

$$
\left\{\begin{array}{c}
\text { emissions }_{P M}=m_{0} \cdot \text { mileage }+n_{0}, 0 \leq \text { mileage } \leq 80,000 \mathrm{~km} \\
\text { emissions }_{P M}=m_{1} \cdot \text { mileage }+n_{1}, \text { mileage }>80,000 \mathrm{~km}
\end{array}\right.
$$

where, in this case, parameters $m_{0}, n_{0}$ and $m_{1}, n_{1}$ were the results of a linear interpolation between 0-80,000 km and 80,000-160,000 km, respectively.

The next phase was to extend calculations, via COPERT to vehicle types not covered by IVE (EURO VI and Compressed Natural Gas-NCG engines), after a COPERT-vs-IVE consistency check (further elaborated in Section 3.2.2), and by using conversion factors. This enabled to get an extended set of simplified bilinear functions. This set was then used to "feed" iGREEN, and fully applied to the two case studies to get the results presented in Section 5. All of the above is synthesized in Figure 2. 
Table 3. Data process including variables driving cycles, temperature, slope, mileage (example).

\begin{tabular}{|c|c|c|c|c|c|c|c|c|c|}
\hline \multirow{2}{*}{ Cycle } & \multirow{2}{*}{ Temp } & \multirow{2}{*}{ Slope } & \multicolumn{3}{|c|}{ Mileage } & \multirow[t]{2}{*}{ Max. Emission } & \multicolumn{2}{|c|}{ Until 80k km: Linear Model } & \multirow{2}{*}{$\begin{array}{l}\text { Over 80k km: } \\
\text { Max. Emissions }\end{array}$} \\
\hline & & & $M_{1}$ & $M_{2}$ & $M_{3}$ & & Equation (1) & Equation (2) & \\
\hline \multirow{12}{*}{$\begin{array}{l}\text { Urban } \\
\text { Short }\end{array}$} & \multirow{4}{*}{$20^{\circ} \mathrm{C}$} & $0^{\circ}$ & 621.49 & 1716.27 & 1770.32 & 1770.32 & 14.360 & 621.490 & 1770.32 \\
\hline & & $1^{\circ}$ & 642.79 & 1765.25 & 1753.27 & 1765.25 & 14.031 & 642.790 & 1765.25 \\
\hline & & $2^{\circ}$ & 660.28 & 1814.02 & 1805.7 & 1814.02 & 14.422 & 660.280 & 1814.02 \\
\hline & & $3^{\circ}$ & 678.09 & 1862.75 & 1850.11 & 1862.75 & 14.808 & 678.090 & 1862.75 \\
\hline & \multirow{4}{*}{$25^{\circ} \mathrm{C}$} & $0^{\circ}$ & 677.03 & 1885.87 & 1873.03 & 1885.87 & 15.111 & 677.030 & 1885.87 \\
\hline & & $1^{\circ}$ & 702.28 & 1959.85 & 1943.56 & 1959.85 & 15.720 & 702.280 & 1959.85 \\
\hline & & $2^{\circ}$ & 720.81 & 2009.85 & 1996.21 & 2009.85 & 16.113 & 720.810 & 2009.85 \\
\hline & & $3^{\circ}$ & 739.64 & 2062.81 & 2048.8 & 2062.81 & 16.540 & 739.640 & 2062.81 \\
\hline & \multirow{4}{*}{$30{ }^{\circ} \mathrm{C}$} & $0^{\circ}$ & 722.04 & 2010.46 & 1998.48 & 2010.46 & 16.105 & 722.040 & 2010.46 \\
\hline & & $1^{\circ}$ & 737.97 & 2063.45 & 2049.48 & 2063.45 & 16.569 & 737.970 & 2063.45 \\
\hline & & $2^{\circ}$ & 757.33 & 2116.46 & 2102.09 & 2116.46 & 16.989 & 757.330 & 2116.46 \\
\hline & & $3^{\circ}$ & 776.3 & 2169.4 & 2154.69 & 2169.4 & 17.414 & 776.300 & 2169.4 \\
\hline \multirow{12}{*}{$\begin{array}{l}\text { Urban } \\
\text { Long }\end{array}$} & \multirow{4}{*}{$20^{\circ} \mathrm{C}$} & $0^{\circ}$ & 481.47 & 1321.41 & 1312.34 & 1321.41 & 10.499 & 481.470 & 1321.41 \\
\hline & & $1^{\circ}$ & 509.61 & 1396.47 & 1386.98 & 1396.47 & 11.086 & 509.610 & 1396.47 \\
\hline & & $2^{\circ}$ & 536.41 & 1471.58 & 1461.59 & 1471.58 & 11.690 & 536.410 & 1471.58 \\
\hline & & $3^{\circ}$ & 563.07 & 1546.64 & 1536.22 & 1546.64 & 12.295 & 563.070 & 1546.64 \\
\hline & \multirow{4}{*}{$25^{\circ} \mathrm{C}$} & $0^{\circ}$ & 488.16 & 1348.86 & 1339.72 & 1348.86 & 10.759 & 488.160 & 1348.86 \\
\hline & & $1^{\circ}$ & 514.54 & 1423.99 & 1414.32 & 1423.99 & 11.368 & 514.540 & 1423.99 \\
\hline & & $2^{\circ}$ & 541.63 & 1499.13 & 1496 & 1499.13 & 11.969 & 541.630 & 1499.13 \\
\hline & & $3^{\circ}$ & 569.11 & 1574.17 & 1563.51 & 1574.17 & 12.563 & 569.110 & 1574.17 \\
\hline & \multirow{4}{*}{$30^{\circ} \mathrm{C}$} & $0^{\circ}$ & 512.29 & 1418.75 & 1409.13 & 1418.75 & 11.331 & 512.290 & 1418.75 \\
\hline & & $1^{\circ}$ & 540.2 & 1493.89 & 1483.76 & 1493.89 & 11.921 & 540.200 & 1493.89 \\
\hline & & $2^{\circ}$ & 568.3 & 1569.02 & 1558.38 & 1569.02 & 12.509 & 568.300 & 1569.02 \\
\hline & & $3^{\circ}$ & 593.94 & 1640.09 & 1632.96 & 1640.09 & 13.077 & 593.940 & 1640.09 \\
\hline \multirow{12}{*}{$\begin{array}{l}\text { Extra } \\
\text { Urban }\end{array}$} & \multirow{5}{*}{$20^{\circ} \mathrm{C}$} & $0^{\circ}$ & 553.49 & 1479.61 & 1478.59 & 1479.61 & 11.577 & 553.490 & 1479.61 \\
\hline & & $1^{\circ}$ & 591.38 & 1580.68 & 1569.96 & 1580.68 & 12.366 & 591.380 & 1580.68 \\
\hline & & $2^{\circ}$ & 629.25 & 1681.71 & 1670.34 & 1681.71 & 13.156 & 629.250 & 1681.71 \\
\hline & & $3^{\circ}$ & 667.17 & 1782.81 & 1770.62 & 1782.81 & 13.946 & 667.170 & 1782.81 \\
\hline & & $0^{\circ}$ & 551.69 & 1508.13 & 1517.92 & 1517.92 & 12.078 & 551.690 & 1517.92 \\
\hline & \multirow{3}{*}{$25^{\circ} \mathrm{C}$} & $1^{\circ}$ & 589.75 & 1609.21 & 1598.29 & 1609.21 & 12.743 & 589.750 & 1609.21 \\
\hline & & $2^{\circ}$ & 626.54 & 1710.27 & 1698.66 & 1710.27 & 13.547 & 626.540 & 1710.27 \\
\hline & & $3^{\circ}$ & 663.49 & 1811.25 & 1798.97 & 1811.25 & 14.347 & 663.490 & 1811.25 \\
\hline & \multirow{4}{*}{$30^{\circ} \mathrm{C}$} & $0^{\circ}$ & 580.6 & 1584.57 & 1573.8 & 1584.57 & 12.550 & 580.600 & 1584.57 \\
\hline & & $1^{\circ}$ & 618.42 & 1685.66 & 1664 & 1685.66 & 13.341 & 618.420 & 1685.66 \\
\hline & & $2^{\circ}$ & 654.59 & 1786.7 & 1774.57 & 1786.7 & 14.151 & 654.590 & 1786.7 \\
\hline & & $3^{\circ}$ & 693.45 & 1887.66 & 1874.84 & 1887.66 & 14.928 & 693.450 & 1887.66 \\
\hline
\end{tabular}

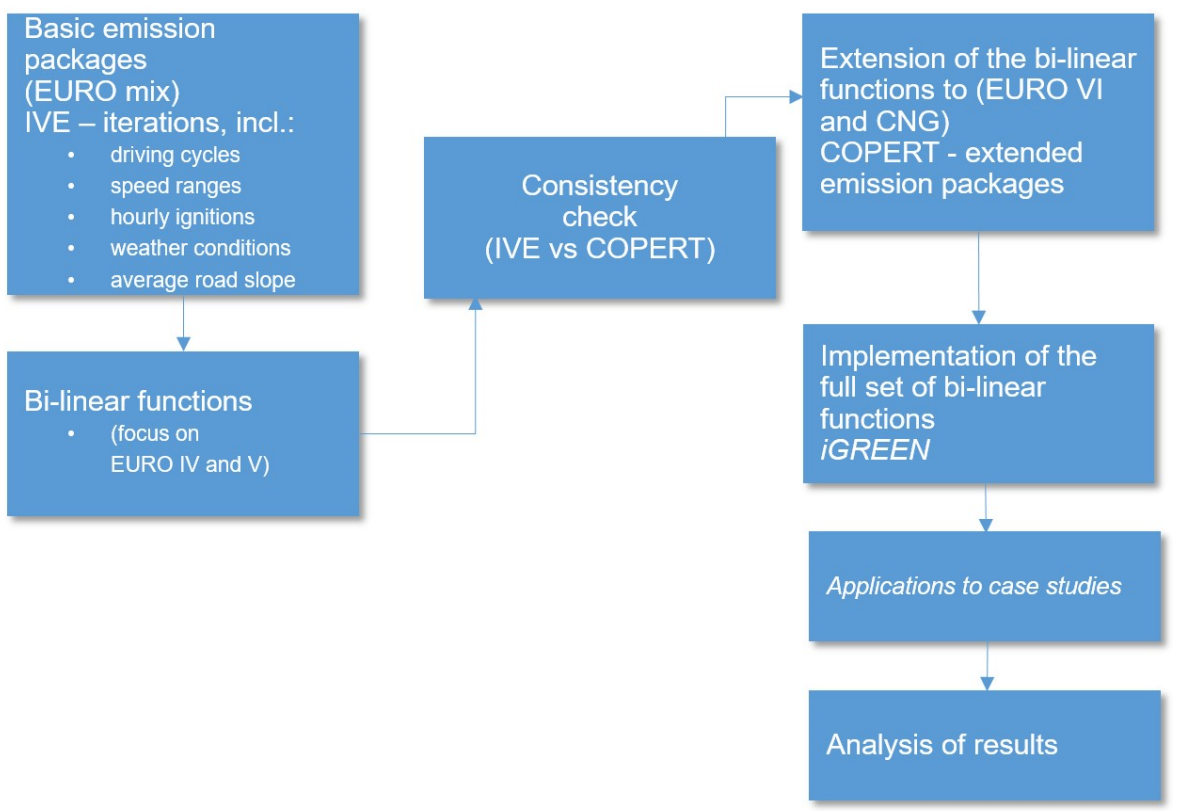

Figure 2. The adopted methodological steps. 


\subsubsection{The Selection of the Case Studies}

The selection of the case studies was coherent with test features required to enable a full application of the $i G R E E N$ procedures. More specifically, the requirements were to assess fleets under real operational scenarios, with mixed EURO-engine vehicles (and possibly even older ones), and protracted mileage, consistently with the three $M_{n}$ variables. In turn, case studies' eligibility was dictated by a full supply, all year round, with peak and off-peak operations; urban environments as service scenarios; hilly and flat morphologies, differences in weather conditions. Consistently with all of the above, iGREEN was tested and calibrated first in Olbia, a provincial town, in the north-eastern area of the Sardinia island, and then in Cuneo, another provincial town in Piedmont, in northern mainland Italy, both described in Section 4.

For both cases, iGREEN estimated $\mathrm{CO}_{2}, \mathrm{NO}_{\mathrm{x}}, \mathrm{CO}, \mathrm{PM}, \mathrm{SO}_{\mathrm{x}}$, and $\mathrm{NH}_{3}$ pollutant emissions, as mandated by the national and supranational regulations on air quality in urban areas. The measurement plan developed for the EBSF_2 test in Ravenna, abovementioned, where the similar pollution package was assessed, was considered for designing the test conditions in both Olbia and Cuneo.

\subsubsection{Specific Methodological Requirements}

Being COPERT and IVE developed under different "umbrellas" (the former as the EEA's tool, the latter outside Europe), a compatibility check was needed in sight of their merging into $i G R E E N$. Therefore, a specific IVE validation under common parameters for EURO IV and V standards was also carried out, to avoid inconsistencies with COPERT. This included for major pollutants $\mathrm{CO}_{2}, \mathrm{NO}_{\mathrm{x}}, \mathrm{CO}$, and $\mathrm{NH}_{3}$, as both processed by IVE and COPERT. Table 4 reports the input data used in this validation step; they describe EURO IV and EURO V diesel buses, in the 15-18t weight class, and according with fuel metal contents in various percentages.

Table 4. Input data for the validation (EURO IV and V buses).

\begin{tabular}{ccc}
\hline Main Validation Data & Value & Unit \\
\hline Operational Input Parameters & \\
Mean activity (as annual average) & 60,000 & $\mathrm{~km}$ \\
Life cumulative activity (sum of annual averages) & 300,000 & $\mathrm{~km}$ \\
Share-urban peak & 15 & $\%$ \\
Share-urban off peak & 85 & $\%$ \\
Speed-urban peak & 15 & $\mathrm{~km} / \mathrm{h}$ \\
Speed-urban off peak & 25 & $\mathrm{~km} / \mathrm{h}$ \\
Energy content Fuel Input Parameters & & $\mathrm{MJ} / \mathrm{kg}$ \\
H:C ratio & 42.6950 & \\
O:C ratio & 1.86 & \\
Density & 0 & $\mathrm{~kg} / \mathrm{m}^{3}$ \\
\hline
\end{tabular}

The data from Table 4 typically enable the COPERT estimation process for the yearly pollutant emissions in tons. IVE, however, includes five supplementary inputs (partly introduced in Section 3.1), i.e.,

- average hourly speed;

- amount of engine ignitions;

- $\quad$ vehicle specific power-VSP;

- $\quad$ engine stress-ES;

- "bins".

The relevance of parameters like the average hourly speed and the number of ignitions occurring within a range of regular operations can be rather intuitive, but VSP and ES (and the associated "bins") describe major conditions for the accuracy of the assessment. VSP is designed to compute effects on emissions from aerodynamic drag and rolling resistance, 
as it correlates speed, accelerations, road grade and altitude [57,58]; as such it was also relevant in the selection of the case studies. ES, in turn, describes the engine's conditions while operating. For a given bus, VSP and ES rely on an on-board GPS to collect the needed data. Once such data are collected, it is then possible to proceed with the "bins" process. "Bins" are sets of emissions variations, and IVE associates bin or VPS conditions with a given correction factors. To determine the suitable set of "bin" values (in percentages) to use in the calculations it is possible to use many references available in literature (for the case in hand [59-61]). Once prepared all of the above, the compatibility analysis (or consistency check in Figure 2) was carried out, which led to the simulated emission results for the three mileage categories $M_{n}$, presented in Table 5.

Table 5. Results from the compatibility analysis.

\begin{tabular}{|c|c|c|c|c|}
\hline \multicolumn{3}{|c|}{ EURO IV } & \multicolumn{2}{|c|}{ EURO V } \\
\hline \multicolumn{5}{|c|}{$M_{1}(<80 \mathrm{~K} \mathrm{~km})$} \\
\hline Pollutant Emitted ( $t /$ year) & IVE & COPERT & IVE & COPERT \\
\hline $\mathrm{CO}_{2}$ & 21.850 & 59.094 & 21.850 & 53.394 \\
\hline $\mathrm{NO}_{\mathrm{x}}$ & 0.3587 & 0.3777 & 0.2044 & 0.4224 \\
\hline $\mathrm{CO}$ & 0.0128 & 0.0776 & 0.0128 & 0.1348 \\
\hline $\mathrm{NH}_{3}$ & 0.0012 & 0.0002 & 0.00126 & 0.00066 \\
\hline \multicolumn{5}{|c|}{$M_{2}(80-160 \mathrm{~K} \mathrm{~km})$} \\
\hline Pollutant Emitted ( $t /$ year) & IVE & COPERT & IVE & COPERT \\
\hline $\mathrm{CO}_{2}$ & 54.192 & 59.094 & 54.1926 & 53.3945 \\
\hline $\mathrm{NO}_{\mathrm{x}}$ & 0.3636 & 0.3777 & 0.2072 & 0.4224 \\
\hline $\mathrm{CO}$ & 0.0134 & 0.0776 & 0.01349 & 0.1348 \\
\hline $\mathrm{NH}_{3}$ & 0.0012 & 0.0002 & 0.00126 & 0.00066 \\
\hline \multicolumn{5}{|c|}{$M_{3}(>160 \mathrm{~K} \mathrm{~km})$} \\
\hline Pollutant Emitted ( $t /$ year) & IVE & COPERT & IVE & COPERT \\
\hline $\mathrm{CO}_{2}$ & 53.823 & 59.094 & 53.823 & 53.3945 \\
\hline $\mathrm{NO}_{\mathrm{x}}$ & 0.3710 & 0.3777 & 0.2115 & 0.4224 \\
\hline $\mathrm{CO}$ & 0.0144 & 0.0776 & 0.0144 & 0.1348 \\
\hline $\mathrm{NH}_{3}$ & 0.0012 & 0.0002 & 0.00126 & 0.00066 \\
\hline
\end{tabular}

As expected, variations occurred, but similar results were specifically achieved for $\mathrm{CO}_{2}$, for the $M_{2}$ and $M_{3}$ mileage classes, i.e., in case of vehicle's protracted mileage or age, for $\mathrm{NO}_{\mathrm{x}}$, with an assessment was similar for EURO IV engines, and for $\mathrm{CO}$ for what concerned the EURO V's three mileage classes.

\section{The Case Studies}

The results from Table 5 prompted a further refinement for $i G R E E N$, which at this point was mature for the case-study application. This was, obviously, conceived primarily to test the $i G R E E N$ reliability in estimating emissions, but also to assess the feasibility to embed the $i G R E E N$ functions within the maintenance software already available, and its user-friendliness.

The selection of the two case studies was driven by several requisites: availability of full sets data to run $i G R E E N$; test areas representative of the problems associated with bus fleets' obsolescence and protracted mileage; operators' willingness to bank on the GREEN results to acknowledge the emissions problems.

The case-study application was a two-step process: an initial, master trial in Olbia (about 60,000 inhabitants), and a follow-up in Cuneo (about 56,000 inhabitants). The two case studies complement each other, being Cuneo a typical middle-size town in northern Italy, with public transport servicing both central areas and residential suburban districts, and the insular port town of Olbia, a major destination for the ferry connections from mainland Italy and the gate to many tourist seaside attractions. More specifically, Olbia can serve as a case in point to assess emissions in peak time services occurring in hot summer periods, whereas Cuneo is an example of operations with peaks during wintertime, 
when also severe climate conditions might occur. Both areas provide sound cases for different land morphologies (flatter in Olbia and hillier in Cuneo). Local transit supply is rubber-tired and operations can be considered standard services for middle-size cities in Italy.

\subsection{The Olbia Test}

iGREEN was first tested in the Olbia bus network (Figure 3), with part of the data to process directly made available by the local transit operator and the IT provider.

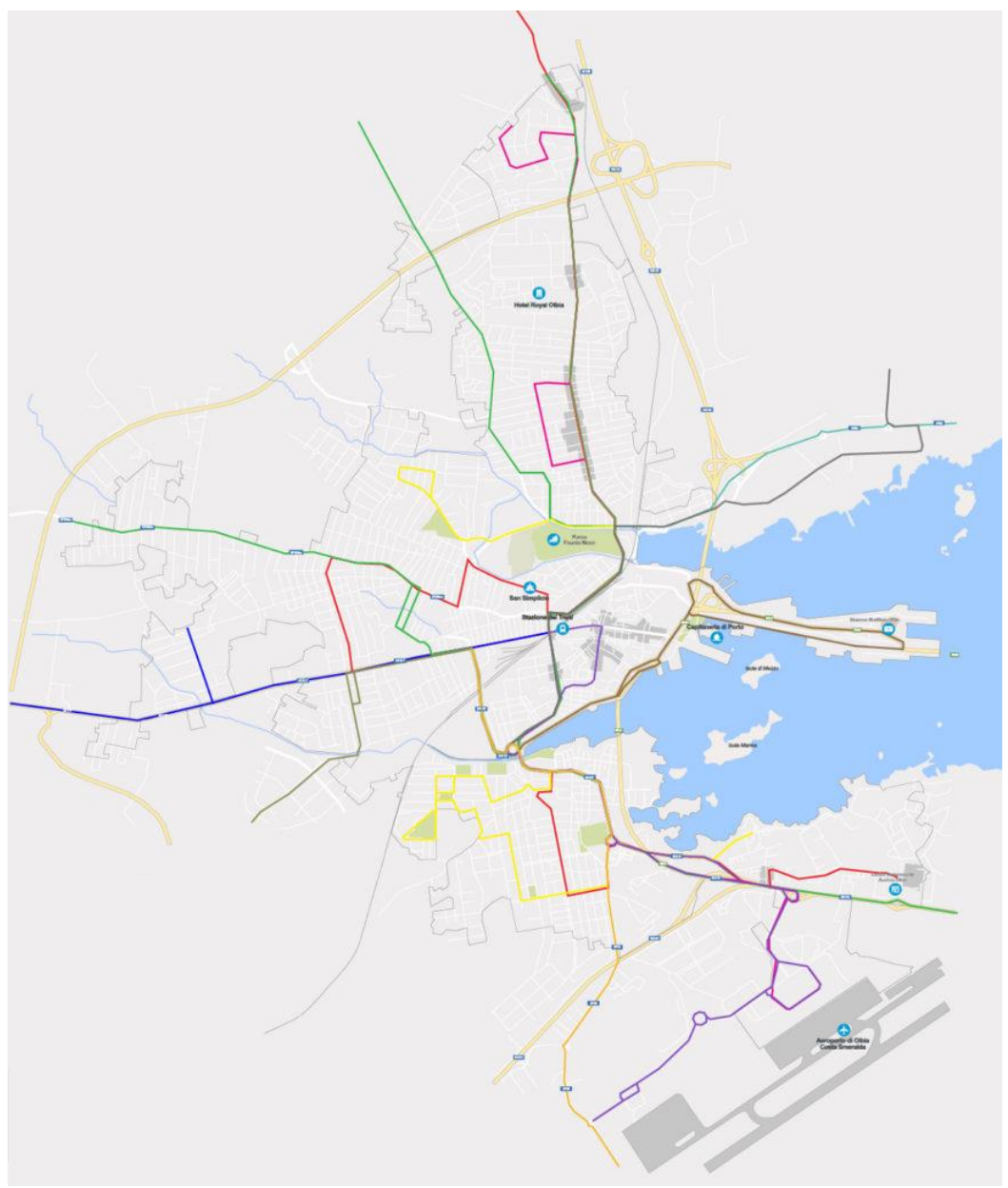

Figure 3. Olbia transit routes.

The trialed fleet was composed by 12 diesel buses, from different models, and servicing different routes so to build a vast array of testing conditions, including that of the use of auxiliaries along the whole daily operations. The vehicles' age was on average 8 years, and the total mileage of each belonged to the iGREEN's $\mathrm{M}_{3}$ class, ranging from 420,000 to $510,000 \mathrm{~km}$. A synthesis of the main operational features is reported in Table 6.

Table 6. Operational features of the tested fleet (selected vehicles and variables).

\begin{tabular}{ccccccc}
\hline $\begin{array}{l}\text { Veh } \\
\text { ID }\end{array}$ & $\begin{array}{c}\text { Max Grade } \\
\text { (m) }\end{array}$ & $\begin{array}{c}\text { Operation Time } \\
\text { (hh:mm) }\end{array}$ & $\begin{array}{c}\text { Ignitions } \\
\text { (Event/Day) }\end{array}$ & $\begin{array}{c}\text { Avg. Speed } \\
\text { Peak Hour } \\
\mathbf{( k m} / \mathbf{h})\end{array}$ & $\begin{array}{c}\text { Avg. Speed } \\
\text { Off-Peak } \\
\mathbf{( k m} / \mathbf{h})\end{array}$ & $\begin{array}{c}\text { Peak Time } \\
\text { Duration } \\
\mathbf{( h h : m m})\end{array}$ \\
\hline 1051 & 10 & $17: 20$ & 38 & 25 & 30 & $3: 15$ \\
1052 & 65 & $12: 10$ & 12 & 31 & 38 & $3: 23$ \\
1053 & 50 & $11: 15$ & 15 & 20 & 26 & $2: 31$ \\
\hline
\end{tabular}


Data collected via GPS on a second-by-second basis (Figure 4) "fed" iGREEN with the needed inputs, e.g., instant speed, grade, etc.

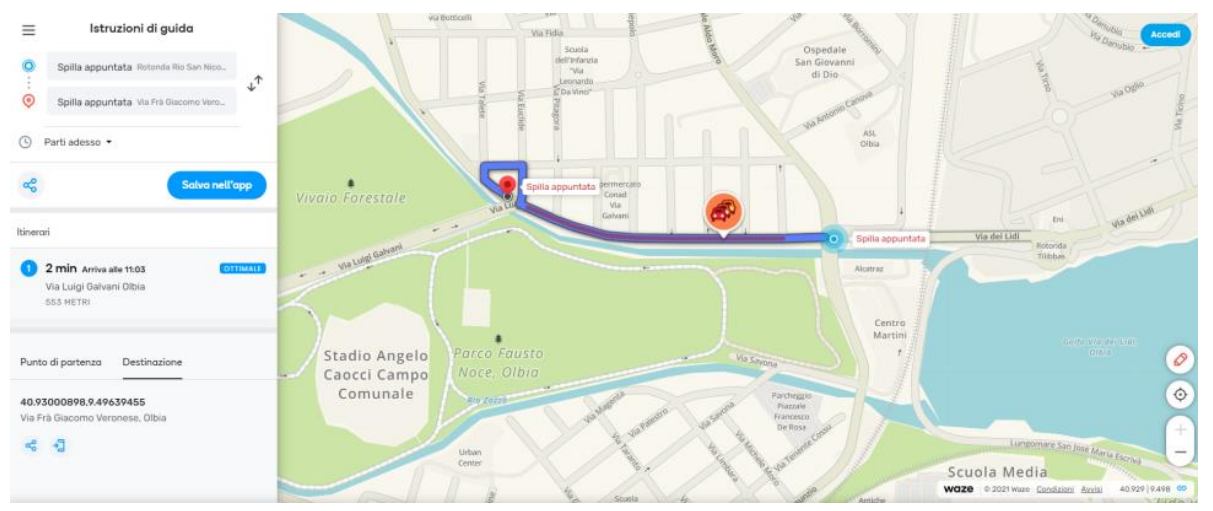

Figure 4. An example of data collection.

The collection fine granularity is also needed to generate inputs for a support software that automatically gives the "bins" for the calculation spreadsheets (Figure 5), coherently with the reference values selected from literature [59-61].
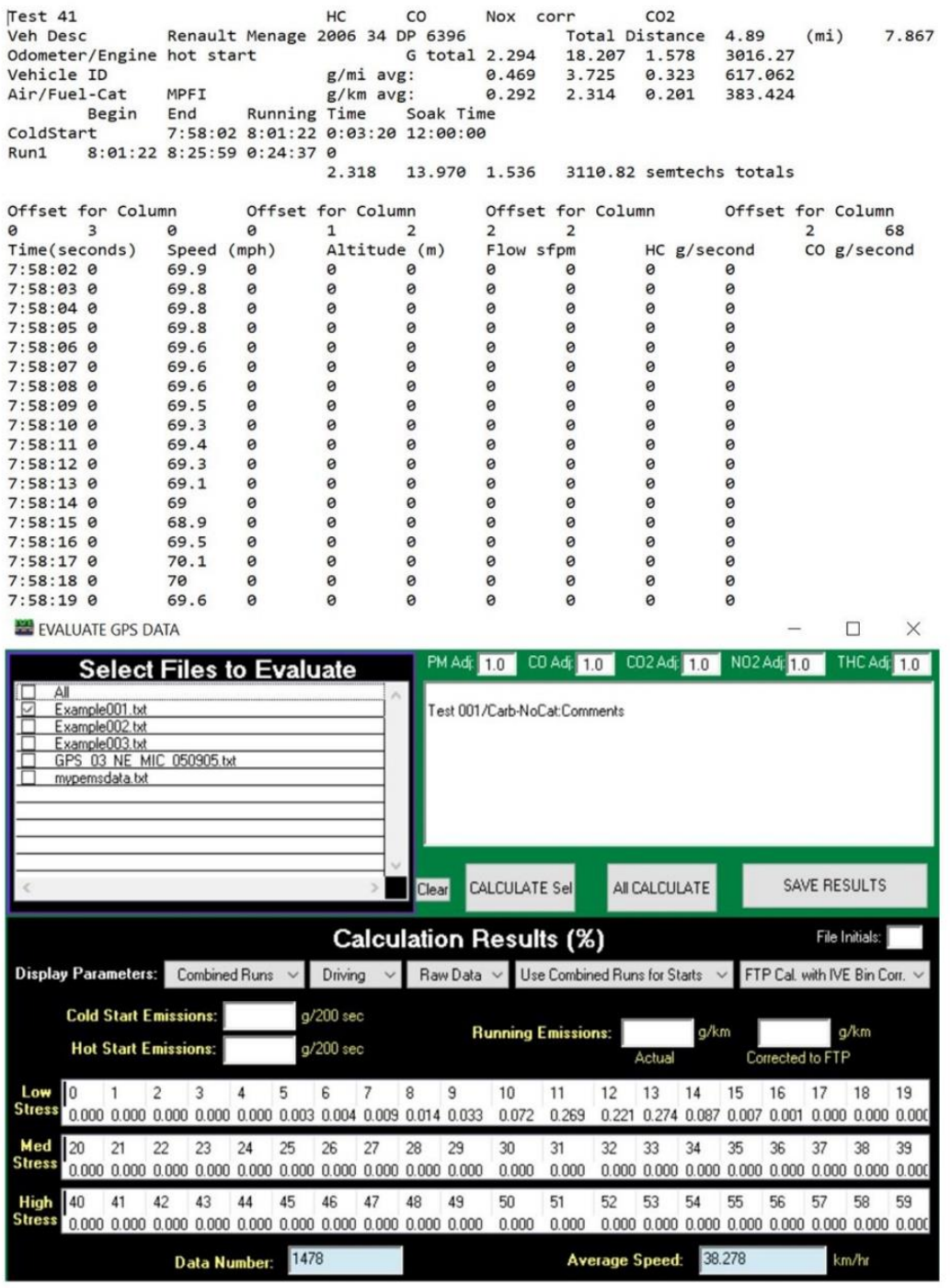

Figure 5. An example of the spreadsheets for the "bin" generation. 
Banking on these datasets, it was possible to run iGREEN 108 times for each trialed route, accounting for 1404 simulations, from which the emission packages were further estimated. As a result, a set of scenarios was built to associate real, recurring operational conditions with the estimated emission packages, as further described in Section 5. To describe the operational conditions as close as possible to reality and have reliable scenarios, a large set of variables, from the datasets, was contemplated consistently with those already introduced in Table 2, i.e.,

- driving cycles (short urban, long urban, and extra urban);

- $\quad$ speed ranges $(12.5,25,30 \mathrm{~km} / \mathrm{h}$, respectively);

- $\quad$ hourly ignitions (2, 1, 0.5 events, respectively);

- weather conditions (air temperature: $20{ }^{\circ} \mathrm{C}, 25^{\circ} \mathrm{C}, 30^{\circ} \mathrm{C}$ );

- $\quad$ average road slope (grade: $0,1,2,3 \%$ ).

All the above-mentioned enabled to build 468 iGREEN matrices, one for each tested vehicle, under the three $M_{n}$ mileage classes, for each EURO standards analyzed and for each of the six pollutants presented in Table 2, i.e., $\mathrm{CO}_{2}, \mathrm{NO}_{\mathrm{x}}, \mathrm{CO}, \mathrm{PM}, \mathrm{SO}_{\mathrm{x}}$, and $\mathrm{NH}_{3}$.

\section{Creating the Software Interface for $i G R E E N$}

As noted earlier, one of the reasons for designing iGREEN was to provide the already available maintenance software's customers with additional functions to assess the emissions generated by the fleet they manage. In this case, the goal is to have the users (the operators) getting their emissions results by a reduced data entry based on well-known data (e.g., EURO standard, slope, type of vehicle, temperature, driving cycle).

The specific scenario-building task in Olbia was also developed bearing this additional goal in mind. Therefore, all Olbia dataset's variables and options were assessed in terms of their transferability to the software interface. The designed procedure (Figure 6) is to have users enter data for two menus: "General Settings" and "Operations" and have iGREEN providing the daily emissions for the given vehicle, according to such entered options. Further updating is also possible: for example, the user might assess emission variations by changing some operational features, typically the amount of service hours, or operational days, or including more vehicles.

More specifically, once data are entered, iGREEN identifies a single matrix, among the final set of 156 simulation matrixes available with different parameters' dataset for any of the pollutants considered.

\subsection{The Cuneo Test}

The Olbia results were considered more than satisfactory, but to further fine-tune the maintenance software iGREEN was to be embedded within, and to increase the quality of inputs, one more case study, Cuneo, was selected. Approach, methodology and data process did not vary. Again, in this case a set of six different routes were considered with a fleet of vehicles similar per mixed types of engines and EURO-compliances to that of Olbia. In this case, emphasis was placed on analyzing the specific local characteristics (on-board occupancy, in some cases higher than in Olbia, empty runs from/to the garage, in terms of mileage and time spent, etc.) and assessing their effects in the generation of pollutant emissions. A comprehensive and comparative analysis with both case studies will be provided in Section 5. The Cuneo test was important to improve the final iGREEN functions in the maintenance software, after the initial application to the Olbia fleet, and finalizing the interface's user-friendliness. 


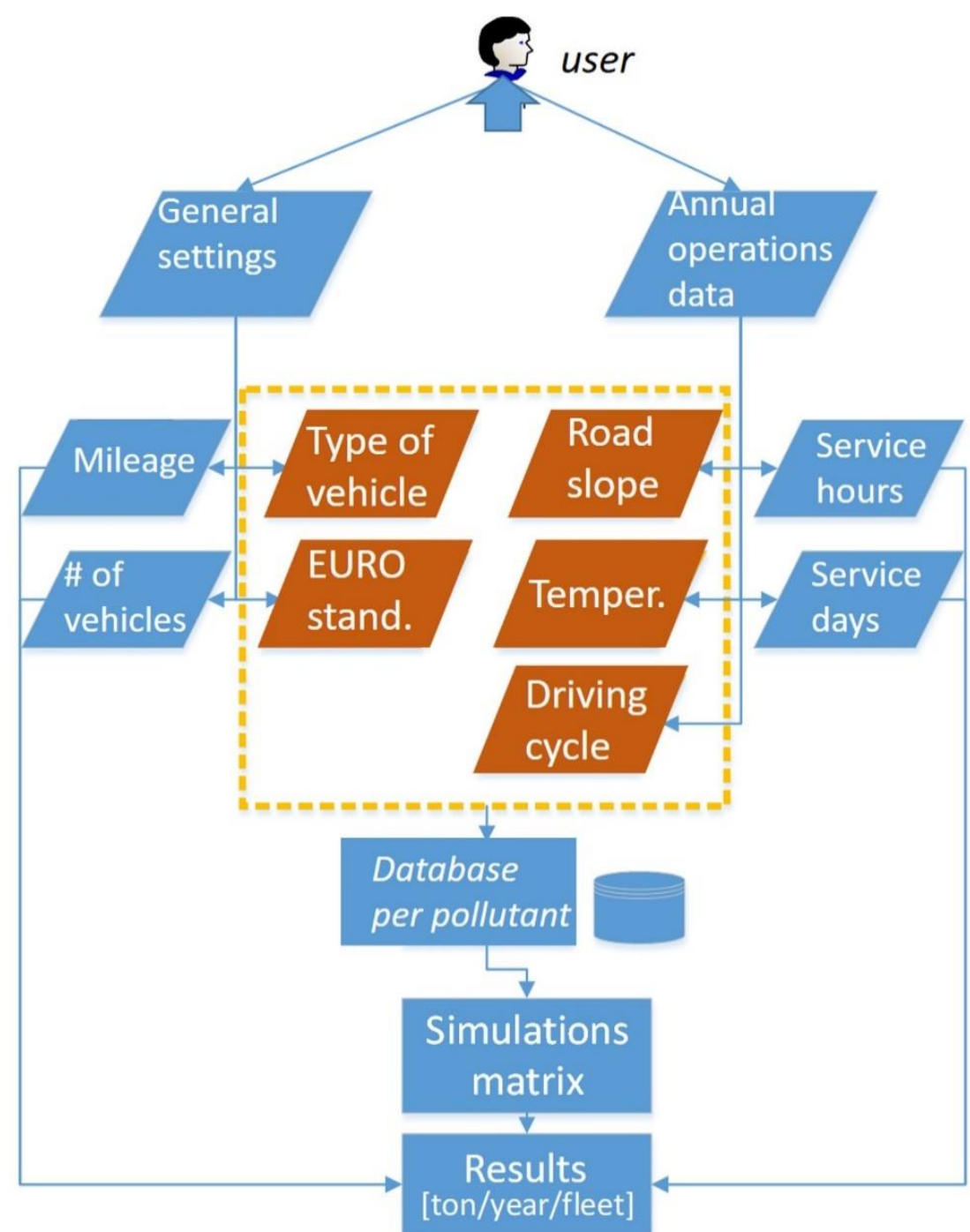

Figure 6. The software interface concept.

\section{The Results Achieved}

iGREEN was run for both Olbia and Cuneo, with two specific methodological goals; first to assess the actual trend of pollutant emissions when mileage gets higher and other variables change; secondly, to compare the results achieved in the two cities to highlight similarities and/or discrepancies. The former relied on the possibility to achieve coherent and homogeneous results in the emissions' trends simulated by iGREEN and claim the approach and the methodology scientifically sound; the latter was targeted to assess how much pollution could be emitted by the local fleets according to the type and quality of vehicles and operations.

\subsection{Emissions Variation Trends}

The emission trends observed for Olbia were confirmed also in the Cuneo case, and both enable to highlight some very specific emission "behaviors" due to the variation of the main parameters $\left(M_{n}\right.$, slope, temperature, etc.). Taking the set of results from Olbia as the case in point, it is possible to observe that the "flat" trend observed in Figure 1 as an example is far from reality, although each pollutant has its own specific trend.

Figure 7 shows that carbon dioxide emissions typically generated by EURO IV and EURO V engines do actually increase with mileage, but when moving from $M_{1}$ to $M_{2}$, i.e., when passing the $80,000 \mathrm{~km}$ threshold, the trend stabilizes in all the driving cycles. In a sensitivity analysis where the effects of grade and temperature variations are considered, 
a 4-5\% increase in the $\mathrm{CO}_{2}$ emissions is observed for each $5{ }^{\circ} \mathrm{C}$-increase in the temperature; this means that severe climate conditions can have a worsening effect (especially in summertimes early mornings or wintertimes afternoons, when temperature rapidly varies). Even more sensitive are the $\mathrm{CO}_{2}$ emissions to grade variations, as they increase by $5-6 \%$ in the long urban and extra urban cycles, for every grade (in \%).

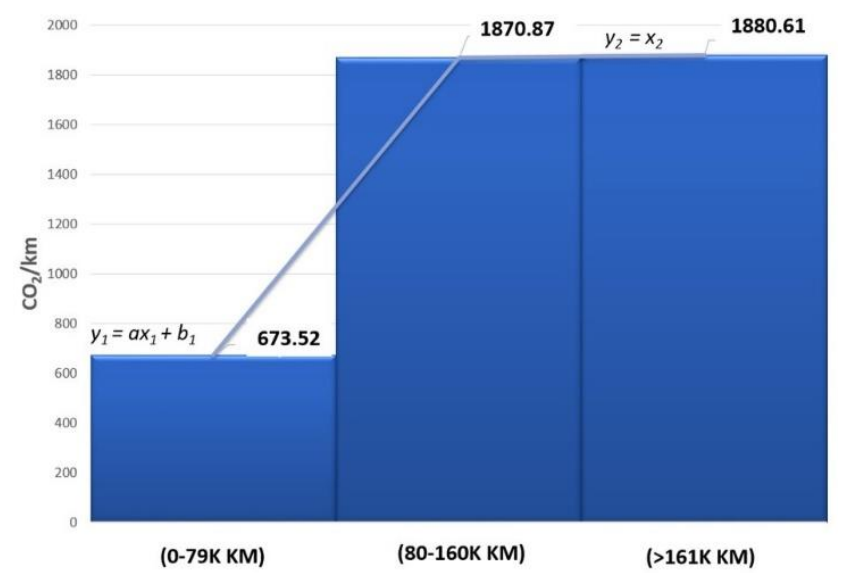

Figure 7. $\mathrm{CO}_{2}$ emissions trend.

$\mathrm{NO}_{\mathrm{x}}$ emissions trend is more mileage sensitive. Figure 8 shows a variation for each mileage class considered, with emissions increasing by $1.4 \%$ when passing from $M_{1}$ to $M_{2}$, and up to $2 \%$ when reaching $M_{3}$ and over. In turn, temperature effects markedly differ from those observed for carbon dioxide, and changes are observed also among the EURO standards. For example, at $20^{\circ} \mathrm{C}$, temperature does not specifically affect nitrogen oxides emissions. However, EURO IV engines show a slight decrease when the temperature reaches $25^{\circ} \mathrm{C}$. For EURO V the temperature's "reducing effect" is clearer: at $25^{\circ} \mathrm{C}$ emissions are $7 \%$ less than at $20^{\circ} \mathrm{C}$. The decreasing trend becomes more evident at $30^{\circ} \mathrm{C}$, with $5 \%$ and $6 \%$ reductions, for EURO IV and EURO V, respectively.

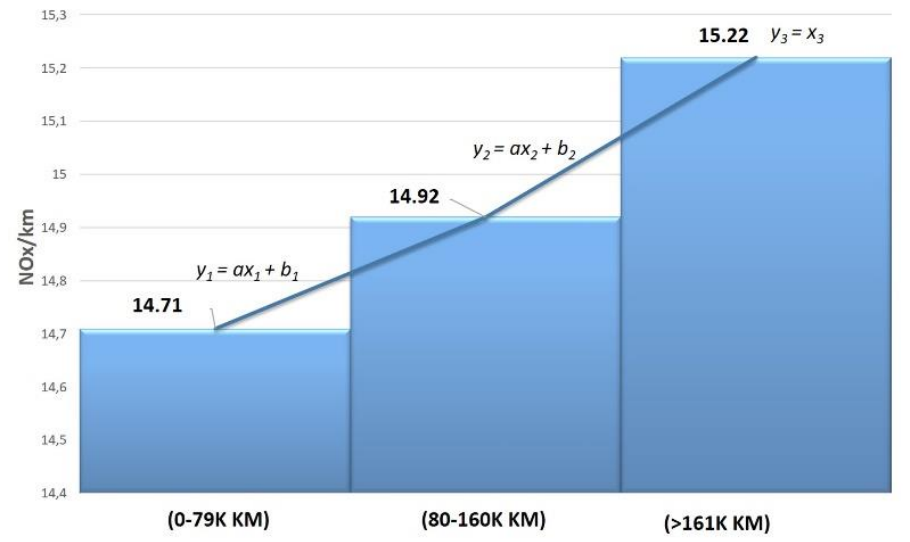

Figure 8. $\mathrm{NO}_{\mathrm{x}}$ emissions trend.

Still for nitrogen oxides emissions, those observed in the long urban cycles are minor compared to those from both the short urban and extra urban cycles, in line with the same trend observed for passenger cars in literature $[62,63]$ and explained by the relationship between emissions and speed. Additionally, particulate matter (PM) emissions trends are consistent with what is observed in literature for passenger cars, but after 160,000 km, the trend becomes exponential.

The results from $\mathrm{CO}$ emissions simulation definitively show that the trend in Figure 1 is mostly unlikely, and that the actual one is similar to the nitrogen oxides. Variations when passing from one mileage class to another are evident; more specifically a $4.5 \%$ increase 
is observed when passing from $\mathrm{M}_{1}$ to $\mathrm{M}_{2}$, and a $6 \%$ one when passing from the latter to $\mathrm{M}_{3}$; however, within $\mathrm{M}_{3}$, no marked increases seem to occur immediately after $161,000 \mathrm{~km}$. Temperature and slopes affect carbon dioxide emissions. When passing from 25 to $30{ }^{\circ} \mathrm{C}$, emissions increase by $3 \%$ and a per-kilometer increment by $1.5 \%$ and $3.3 \%$ for every grade (in \%), respectively, for short urban and extra urban cycles.

Unlike the pollutants thus far described, sulphur oxides emissions decrease with mileage (Figure 9). This trend can be easily explained if the $\mathrm{SO}_{\mathrm{x}}$ composition is considered: this is $98 \% \mathrm{SO}_{2}$, which degrades fast after $80,000 \mathrm{~km} \mathrm{[64].}$

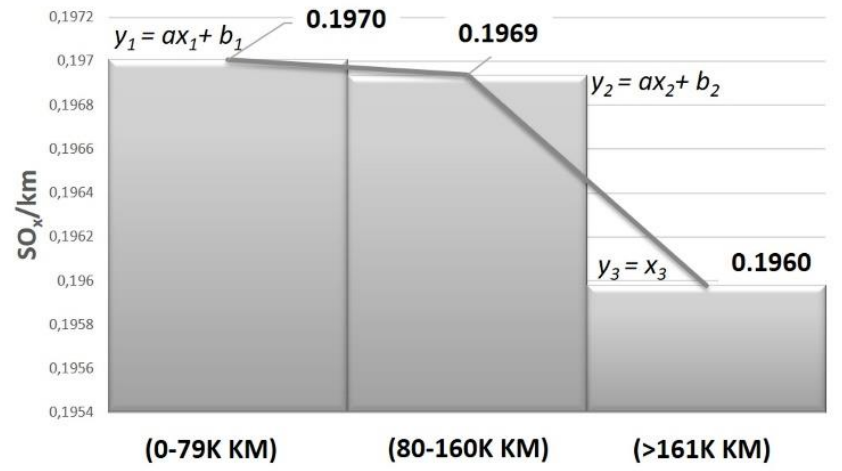

Figure 9. $\mathrm{SO}_{\mathrm{x}}$ emissions trend.

Last to consider are $\mathrm{NH}_{3}$, i.e., ammonia emissions, generated mostly in the cold-start stage. This pollutant is very harmful as it gives rise to $\mathrm{PM}_{2.5}$. Ammonia emissions seem to be unaffected by mileage or vehicle age, and decrease when temperature raises.

\subsection{Cross-Case and Cross-Model Comparisons}

As mentioned, the above-reported trends were confirmed in both Olbia and Cuneo cases, thus validating the $i G R E E N$ approach and methodology. The next goal was to have an accurate estimation of the amount of pollutants emitted in each case study. The following results from the cross-case analysis are based on average values, estimated on a yearlybasis, considering for both cases similar and comparable types of operations and fleets (peak and off-peak features, daily service duration, number of routes, EURO standards availability in the test fleets, etc.).

Figure 10 shows that the overall pollutant package in Olbia is particularly affected by $\mathrm{CO}$ and the nitrogen components, ammonia especially; likewise, carbon dioxide has the same relevance in the Cuneo case, where also the amount of $\mathrm{SO}_{\mathrm{x}}$ emissions is greater than in Olbia.

The variations above reported are partly due to differences in operations and the local managers can benefit from the achieved data to improve, for example, maintenance operations. The high value for ammonia in Olbia might prompt maintenance staff to solve cold-start problems. In turn, carbon dioxide's higher values detected in Cuneo can be associated with the hillier topography of this area, if compared to Olbia, which results in engines' more demanding performance, as noted in literature [65]. This introduces one more important issue: the relevance of emission assessment as a way to improve the quality of operations, discussed in the next subsection.

To conclude, results were also compared to those achievable by the application of both IVE and COPERT in the two case studies. To this end, local test fleets were composed by a selection of EURO V and VI vehicles to avoid COPERT's issue highlighted in Figure 1, for older vehicles. This resulting cross-model fleets' average operational figures correspond to a daily mileage of around $250 \mathrm{~km}$, with $23 \mathrm{~km} / \mathrm{h}$ as peak-time commercial speed.

The results for the $\mathrm{CO}_{2}$ emissions, as an example, show discrepancies among the three models due to the overlapping limitations of both COPERT and IVE (Figure 11). The lower values simulated by IVE rely on the problem that this model is not able to process the EURO VI technology, therefore, the results reflect this underestimation, considering that one third of the overall cross-model fleet is composed by this type of vehicles. In turn, 
results from COPERT are affected by the $80,000-\mathrm{km}$ mileage limitation, as the cross-model fleets would be placed in the $\mathrm{M}_{2}$ mileage class. It is rather intuitive that COPERT seems to "align" emissions to a reduced mileage range, and to associate with the EURO V vehicles most of the emission outputs. This comparison between IVE and COPERT is one more line of evidence of the reliability of both and of their sensitivity to specific operational features. However, if results from both COPERT and IVE are compared to those from $i G R E E N$, the interpretation of Figure 11 suggests the more comprehensiveness of the latter. iGREEN values are not just an average of COPERT's and IVE's, or "something in between"; nor the $i G R E E N$ 's lower figures can be considered a kind of underestimation of the two. Figure 11 evidences that $i G R E E N$, for the case in hand, is able to (a) estimate emissions according to the actual mileage range and (b) "acknowledge" the more eco-friendliness of the EURO VI vehicles, rebalancing the overall $\mathrm{CO}_{2}$ emission results.
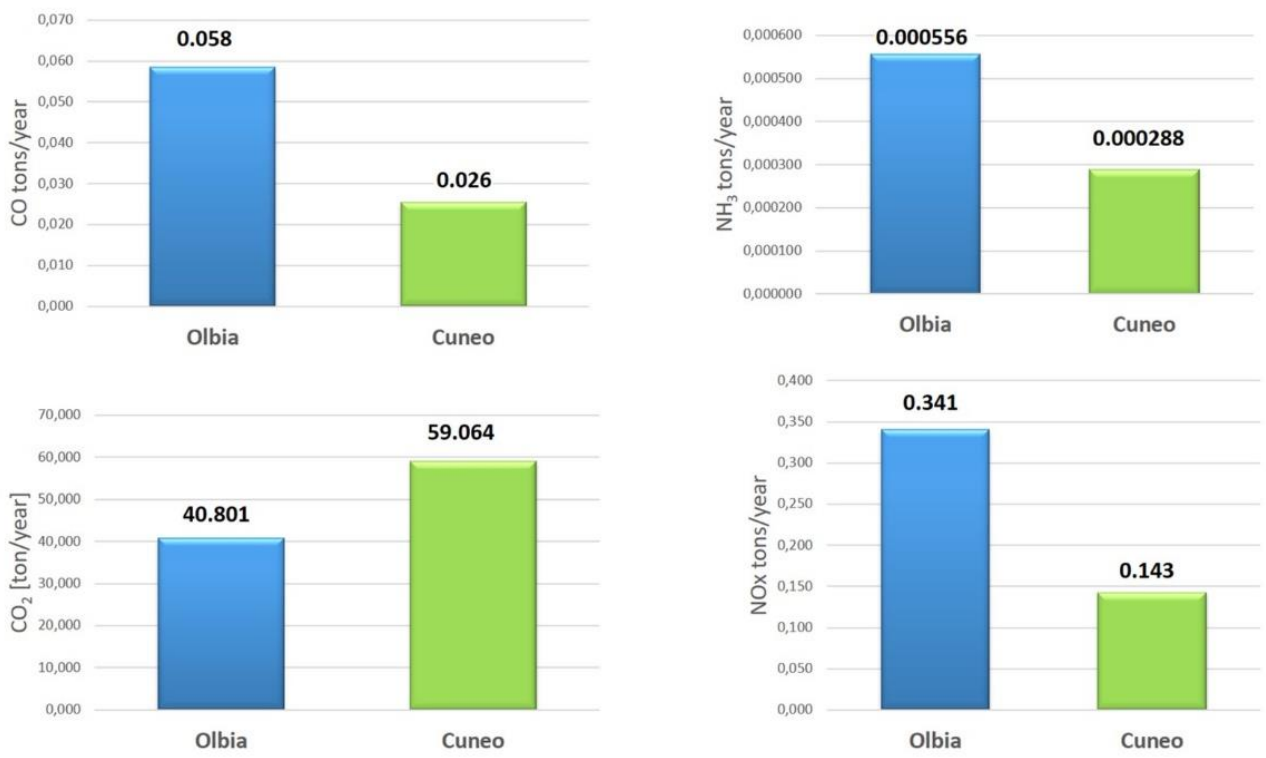

Figure 10. $\mathrm{CO}, \mathrm{CO}_{2}, \mathrm{NH}_{3}$, and $\mathrm{NO}_{\mathrm{x}}$ emissions comparison.

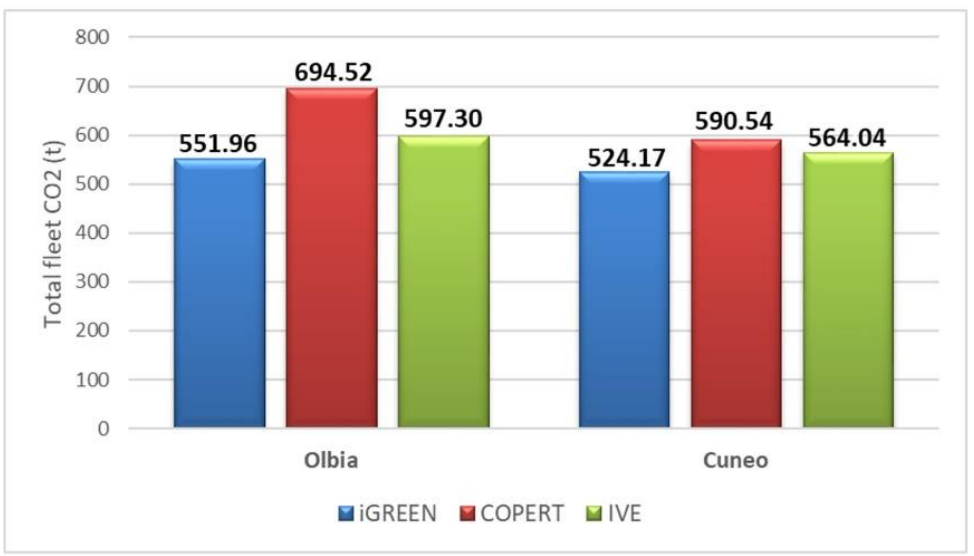

Figure 11. $\mathrm{CO}_{2}$ emissions, cross-model comparison.

However, more analyses and more different fleets are needed to switch from casestudy-based to general evidence.

\subsection{Finalizing iGREEN}

The data collection and the two case studies were also important to finalize iGREEN interface's user-friendliness. Reliability is certainly the top priority when developing a 
tool like iGREEN, but ease of use is important, especially if operators might plan to assess results from the calculated emissions as diagnostics to optimize maintenance operations.

To this end, the iGREEN interface was conceived according to the ultimate user interface (UI) and user experience (UX) advances. The mock-up in Figure 12 is an example of how any UI visual item is designed to facilitate the users' interaction, by simply selecting the initial inputs (driving cycle, temperature, grade, etc.) from basic scroll-down menus in the upper part of the page. Graphics for results are designed to convey clear and univocal information, so to generate a positive UX.

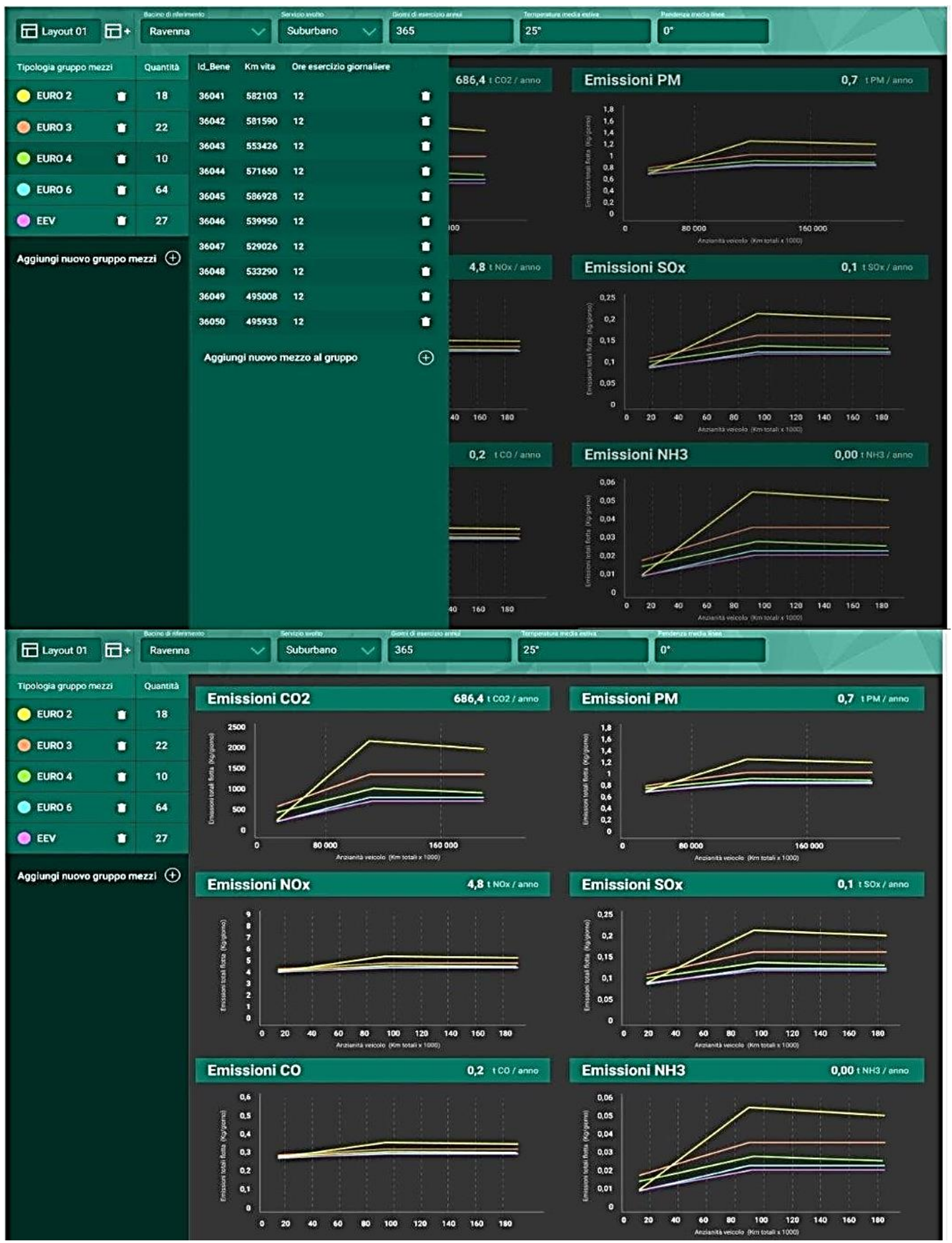

Figure 12. iGREEN interface (mockup). 


\section{Discussion: Will the Environmental Concern Still Be a Priority?}

As stated in the introduction, accurate knowledge of emissions can certainly help public transport operators to cope with the environmental concerns when fleets are composed by old vehicles or problems of protracted mileage become challenging. In meeting such requirement, the $i G R E E N$ approach and results highlight an important issue: to minimize emissions, it is important to acknowledge their magnitude and adjust operations accordingly. A much more affordable solution than retrofitting or fleet renewal.

More specifically, by linking emission trends to specific variables, operators can improve the eco-friendliness of the service. As observed, engines' performance, road morphology, weather affect the quantity and quality of emissions, which means that operators can redesign the service to minimize their impacts. Simple measures can be implemented to achieve this goal, mostly replanning operations to associate the more polluting (older) vehicles with less challenging operational conditions. For example, operating such poorly performing vehicles on routes with modest slopes or with fewer stops (to reduce dwell times, thus optimizing the use of auxiliaries when doors open); likewise they can be operated preferably when weather conditions are not too extreme to generate additional emissions. Eventually, the knowledge of what types of pollutants are dominant in generating the local emission packages can also improve the quality of the maintenance operations, as each pollutant type can forecast specific problems, thus acting as diagnostic tools. Nitrogen-based emissions can indicate exceeding temperatures reached during combustions, likewise for $\mathrm{CO}$ emissions which can reveal fuel burnt unsuitably. High levels of $\mathrm{SO}_{\mathrm{x}}$ in the emission packages might stress fuel's unsuitable quality, and in general engine oil degraded performance could be one more reason to generate such harmful pollutants [43].

Consequently, providing an easy tool to calculate emissions for buses and analyzing emission trends according to mileage, EURO performance, and driving features can really help transit operators to understand the level of sustainability of the fleets they manage.

However, the recent pandemic raised new priorities which might cast a shadow on the long lamented environmental problem. On the one hand, the improved air quality conditions due to the lockdowns during the pandemic's first wave (first months in 2020) paradoxically prompted to salute this phenomenon as a "blessing in disguise" [66]. However, such improvement is modest in light of the Paris COP21 mandate, and the way to achieve it unbearable [67].

On the other hand, the spread fear has generated an overall drop of the transit demand and revamped passenger cars. This, in turn, not only begets an expected increase of solo travels, but creates three new imperatives for public transport operations: Reduce, Arrange and Avoid. Social distancing implies to reduce on-board capacity, which is translated in a diminished number of seats and standing places, certainly improving travel comfort and perceived safety. However, reduced capacity does not work when supply is not increased to compensate it, which introduces the second imperative, that to arrange operations, due to the long time needed to retrofit fleets (onboard layouts and equipment) and adapt services. However, vehicles in general have one more element of weakness generated by the poor availability of "touchless" technologies. Often doors opening is operated, on demand, by pushing buttons, seats can be folded manually, standing can require to hold on to handrails, etc., thus avoid touching surfaces is virtually impossible. Again, recommending frequent handwash and personal protection equipment (PPEs) is a faster response for the transit companies than starting demanding and expensive retrofit operations.

Such three imperatives seem at present so compelling that the whole Research and Development approach thus far deployed might appear useless. Prior to the pandemic, in the last decade, designers and manufacturers' concern was to improve energetic and environmental performance of engines and on-board equipment, namely auxiliaries, so to create on board "acclimatized" environments to minimize heated or cooled air loss; likewise, ergonomics improvements were designed to accommodate passengers in a comfortable way also during packed situations, and even innovations like updated eco-driving systems were conceived to optimize the service under the operational and energetic points of 
view [4,9]. Major efforts were placed in retrofitting old buses in the awareness that a fleet total turnover would be unfeasible for many transport companies. Thus, if in the past, for example, HVAC systems were re-engineered and retrofitted to maximize energy efficiency, now the urgency is to do the same to ensure appropriate fresh air intakes and circulation to supply passengers with a safe on-board travel environment. Likewise, if dwell time at bus stops was critical for the problem of heat loss while doors were open, now it is for the possibility to ensure an adequate fresh air exchange.

The additional research question whether the past environmental and energetic concerns will be neglected in the near future has a very specific reply: preparedness. The lesson learnt during this pandemic is that public transport was unprepared to face the emergency and provide a fast, appropriate reply. To cope with that, in the very near future, researchers and manufacturers are very likely to quickly focus on the development and provision of safer, healthier travel conditions and contactless operations will certainly be central [68]. This will be only the first response to create the "new normalcy" everyone is expecting. However, the evidence that climate change could have played a role in the recent pandemics cannot be ignored [69], thus bringing back the focus on the environmental and energetic concerns. Therefore, full preparedness will be claimed only when new and retrofitted vehicles will be equally safe and eco-friendly, comfortable and energy-consoscious, with both well-being and environmental safeguard requirements fully met.

\section{Concluding Remarks}

$i$ GREEN proved, thus far, to be reliable, user-friendly and widely implementable to a vast range of buses, thanks to its comprehensiveness. Results above synthesized are mostly in line with what was already acknowledged for passenger cars, but very less well-known for buses. iGREEN, however, is progressing, addressing an advanced artificial neural networks-based approach, after the recent developments in [70], which could enlarge its potential. This will go hand in hand with the iGREEN implementation in more case studies, to corroborate results and evidence the appropriateness of the cross-model results, reported in Section 5.2.

iGREEN's added value relies, however, on the "philosophy" behind it. The environmental concern is still a priority, even though current circumstances might show otherwise, and consumption patterns must be coherent with that. For many transport companies, retrofitting vehicles is more viable than purchasing new ones, but retrofitting is certainly more expensive than controlling emissions by means of a user-friendly model like $i G R E E N$. The awareness of the actual fleets' emission packages enables bus companies to adapt operations to achieve cleaner performance and optimize maintenance. It also contributes to prolong components and vehicles lifecycles, reduce waste and save (staff and monetary) resources, with the final goal to provide the communities to serve with additional benefits from cleaner operations.

Author Contributions: Conceptualization and methodology: M.V.C.; investigation, M.V.C., P.C.L., M.P.; data curation, E.P., P.C.L., M.P.; resources: E.P., D.V., validation: E.P., P.C.L., M.P.; writingoriginal draft preparation, M.V.C.; visualization: M.V.C., P.C.L.; writing-review and editing, M.V.C., D.V.; supervision: M.V.C. All authors have read and agreed to the published version of the manuscript.

Funding: This research was funded within the activities of a research project between Sapienza University of Rome and PLUSERVICE srl, titled: Elaborazione di procedure di calcolo per la stima delle emissioni inquinanti di flotte di autobus.

Acknowledgments: The authors would like to thank the public transport companies in Olbia and Cuneo who kindly supported this study.

Conflicts of Interest: The authors declare no conflict of interest. 


\section{References}

1. UITP. Global Bus Survey. May 2019. Available online: https://www.uitp.org/publications/global-bus-survey/ (accessed on 10 January 2020).

2. Bloomberg NEF, Electric Vehicle Outlook 2020. Available online: https://about.bnef.com/electric-vehicle-outlook/ (accessed on 27 December 2020).

3. Bousse, Y.; Corazza, M.V.; Arriaga, D.S.; Sessing, G. Electrification of public transport in Europe: Vision and practice from the ELIPTIC project. In Proceedings of the 2018 IEEE International Conference on Environment and Electrical Engineering and 2018 IEEE Industrial and Commercial Power Systems Europe (EEEIC/I\&CPS Europe), Palermo, Italy, 12-15 June 2018; pp. 1-6. [CrossRef]

4. Corazza, M.V.; Guida, U.; Musso, A.; Tozzi, M. From EBSF to EBSF_2: A compelling agenda for the bus of the future: A decade of research for more attractive and sustainable buses. In Proceedings of the 2016 IEEE 16th International Conference on Environment and Electrical Engineering (EEEIC), Florence, Italy, 7-10 June 2016; pp. 1-6. [CrossRef]

5. ASSTRA. Investire nel TPL: Scenari e fabbisogni. February 2019. Available online: https://www.trasporti-italia.com/citta/ convegno-nazionale-asstra-investire-nel-tpl-scenari-e-fabbisogni/37236 (accessed on 10 January 2020).

6. Stempien, J.; Chan, S. Comparative study of fuel cell, battery and hybrid buses for renewable energy constrained areas. J. Power Sources 2017, 340, 347-355. [CrossRef]

7. Meishner, F.; Sauer, D.U. Technical and economic comparison of different electric bus concepts based on actual demonstrations in European cities. IET Electr. Syst. Transp. 2020, 10, 144-153. [CrossRef]

8. Santos, D.; Kokkinogenis, Z.; De Sousa, J.F.; Perrotta, D.; Rossetti, R.J.F. Towards the integration of electric buses in conventional bus fleets. In Proceedings of the 2016 IEEE 19th International Conference on Intelligent Transportation Systems (ITSC), Rio de Janeiro, Brazil, 1-4 November 2016; pp. 88-93. [CrossRef]

9. Musso, A.; Corazza, M.V.; Information, R. Visioning the bus system of the future: Stakeholders' perspective. Transp. Res. Rec. J. Transp. Res. Board 2015, 2533, 109-117. [CrossRef]

10. Bektaş, T.; Laporte, G. The pollution-routing problem. Transp. Res. Part B Methodol. 2011, 45, 1232-1250. [CrossRef]

11. Iris, Ç.; Lam JS, L. A review of energy efficiency in ports: Operational strategies, technologies and energy management systems. Renew. Sustain. Energy Rev. 2019, 112, 170-182. [CrossRef]

12. Venturini, G.; Iris, Ç.; Kontovas, C.A.; Larsen, A. The multi-port berth allocation problem with speed optimization and emission considerations. Transp. Res. Part D Transp. Environ. 2017, 54, 142-159. [CrossRef]

13. Zhang, X.; Lam JS, L.; Iris, Ç. Cold chain shipping mode choice with environmental and financial perspectives. Transp. Res. Part D Transp. Environ. 2020, 87, 102537. [CrossRef]

14. Tsai, W.-H.; Lee, K.-C.; Liu, J.-Y.; Lin, H.-L.; Chou, Y.-W.; Lin, S.-J. A mixed activity-based costing decision model for green airline fleet planning under the constraints of the European Union Emissions Trading Scheme. Energy 2012, 39, 218-226. [CrossRef]

15. Posada, F. CNG Bus Emissions Roadmap: From Euro III to Euro VI; International Council on Clean Transportation: Washington, DC, USA, 2009; p. 5.

16. Nanaki, E.; Koroneos, C.; Roset, J.; Susca, T.; Christensen, T.; Hurtado, S.D.G.; Rybka, A.; Kopitovic, J.; Heidrich, O.; LópezJiménez, P.A. Environmental assessment of 9 European public bus transportation systems. Sustain. Cities Soc. 2017, $28,42-52$. [CrossRef]

17. Li, F.; Zhuang, J.; Cheng, X.; Li, M.; Wang, J.; Yan, Z. Investigation and prediction of heavy-duty diesel passenger bus emissions in Hainan using a COPERT model. Atmosphere 2019, 10, 106. [CrossRef]

18. Jimenez, F.B.P.; Román, A. Urban bus fleet-to-route assignment for pollutant emissions minimization. Transp. Res. Part E Logist. Transp. Rev. 2016, 85, 120-131. [CrossRef]

19. Varella, R.A.; Giechaskiel, B.; Sousa, L.; Duarte, G. Comparison of portable emissions measurement systems (PEMS) with laboratory grade equipment. Appl. Sci. 2018, 8, 1633. [CrossRef]

20. Giechaskiel, B.; Clairotte, M.; Valverde-Morales, V.; Bonnel, P.; Kregar, Z.; Franco, V.; Dilara, P. Framework for the assessment of PEMS (Portable Emissions Measurement Systems) uncertainty. Environ. Res. 2018, 166, 251-260. [CrossRef] [PubMed]

21. Özener, O.; Özkan, M. Fuel consumption and emission evaluation of a rapid bus transport system at different operating conditions. Fuel 2020, 265, 117016. [CrossRef]

22. Yu, H.; Liu, Y.; Li, J.; Liu, H.; Ma, K. Real-Road driving and fuel consumption characteristics of public buses in Southern China. Int. J. Automot. Technol. 2020, 21, 33-40. [CrossRef]

23. Gómez, A.; Fernández-Yáñez, P.; Soriano, J.A.; Sánchez-Rodríguez, L.; Mata, C.; García-Contreras, R.; Armas, O.; Cárdenas, M.D. Comparison of real driving emissions from Euro VI buses with diesel and compressed natural gas fuels. Fuel 2021, $289,119836$. [CrossRef]

24. Kozak, M.; Lijewski, P.; Fuc, P. Exhaust emissions from a city bus fuelled by oxygenated diesel fuel. SAE Tech. Pap. Ser. 2020. [CrossRef]

25. Pan, Y.; Qiao, F.; Tang, K.; Chen, S.; Ukkusuri, S.V. Understanding and estimating the carbon dioxide emissions for urban buses at different road locations: A comparison between new-energy buses and conventional diesel buses. Sci. Total Environ. 2020, 703, 135533. [CrossRef] [PubMed]

26. Rosero, F.; Fonseca, N.; López, J.-M.; Casanova, J. Real-world fuel efficiency and emissions from an urban diesel bus engine under transient operating conditions. Appl. Energy 2020, 261, 114442. [CrossRef] 
27. Franco, V.; Kousoulidou, M.; Muntean, M.; Ntziachristos, L. Road vehicle emission factors development: A review. Atmos. Environ. 2013, 70, 84-97. [CrossRef]

28. Borge García, R.; Lumbreras Martin, J.; Perez Rodriguez, J.; Vedrenne, M.; Andres Almeida, J.M.; Rodriguez Hurtado, M.E. Development of road traffic emission inventories for urban air quality modeling in Madrid (Spain). In Proceedings of the 21st International Emission Inventory Conference Air Quality Challenges: Tackling the Changing Face of Emissions, San Diego, CA, USA, 13-16 April 2015; pp. 1-36.

29. Linton, C.; Grant-Muller, S.; Gale, W.F. Approaches and techniques for modelling CO2 emissions from road transport. Transp. Rev. 2015, 35, 533-553. [CrossRef]

30. Jaworski, A.; Mądziel, M.; Lejda, K. Creating an emission model based on portable emission measurement system for the purpose of a roundabout. Environ. Sci. Pollut. Res. 2019, 26, 21641-21654. [CrossRef]

31. Alkafoury, A.; Bady, M.; Aly, M.H.F.; Negm, A.M. Emissions modeling for road transportation in urban areas: State-of-Art review. In Proceedings of the 23rd International Conference on "Environmental Protection is a Must", Alexandria, Egypt, 11-13 May 2013; pp. 1-16.

32. Boulter, P.G.; McCrae, I.S. ARTEMIS: Assessment and Reliability of Transport Emission Models and Inventory Systems—Final Report; TRL: London, UK, 2007.

33. Boulter, P.G.; McCrae, I.S.; Barlow, T.J. A Review of Instantaneous Emission Models for Road Vehicles; TRL Limited: Wokingham, UK, 2007.

34. Klein, J.; Geilenkirchen, G. Methods for calculating the emissions of transport in the Netherlands. Task Force on Transportation of the Dutch Pollutant Release and Transfer Register; TNO: Utrecht, The Netherlands, 2018.

35. Guor, S.; Zhang, Y.; Cai, G.Q. Study on exhaust emission test of diesel vehicles based on PEMS. Procedia Comput. Sci. 2020, 166, 428-433. [CrossRef]

36. Kliucininkas, L.; Matulevicius, J.; Martuzevicius, D. The life cycle assessment of alternative fuel chains for urban buses and trolleybuses. J. Environ. Manag. 2012, 99, 98-103. [CrossRef]

37. Smit, R.; Kingston, P.; Tooker, R.; Neale, D.; Torr, S.; Harper, R.; O’Brien, E.; Harvest, D.; Wainwright, D. A Brisbane tunnel study to assess the accuracy of Australian motor vehicle emission models and examine the main factors affecting prediction errors. Air Qual. Clim. Chang. 2015, 49, 35-41.

38. Emisia. COPERT 5 Manual; Microsoft Windows. Available online: https://copert.emisia.com/manual/ (accessed on 5 December 2019).

39. Boulter, P.G. Emission Factors 2009: Report 6-Deterioration Factors and Other Modelling Assumption on Road Vehicles; TRL: London, UK, 2009.

40. NAEI-National Atmospheric Emission Inventory. Method for Applying Emission Degradation Correction Factors for the COPERT 4 Nox for Light Duty Petrol Vehicles; Department for Business, Energy and Industrial Strategy: London, UK, 2012.

41. Carbone, D.; Proia, E. (Eds.) EBSF Deliverable—Report on the Energy Efficiency of Bus System; ASSTRA: Rome, Italy, 2013; restricted document, unpublished.

42. EUROSTAT, E.U. Transport in Figures—Statistical Pocketbook 2020; Publications Office of the European Union: Luxembourg, 2020.

43. Corazza, M.V.; Magnalardo, S.; Musso, A.; Petracci, E.; Tozzi, M.; Vasari, D.; De Verdalle, E. Testing an innovative predictive management system for bus fleets: Outcomes from the Ravenna case study. IET Intell. Transp. Syst. 2018, 12, 286-293. [CrossRef]

44. Lents, J.; Davis, N. IVE Model User's Guide, Model and Data Files. Technical Report; US Environmental Protection Agency: Washington, DC, USA, 2009. Available online: http:/ / www.issrc.org (accessed on 16 December 2018).

45. Guo, H.; Zhang, Q.-Y.; Shi, Y.; Wang, D.-H. Evaluation of the International Vehicle Emission (IVE) model with on-road remote sensing measurements. J. Environ. Sci. 2007, 19, 818-826. [CrossRef]

46. Davis, N.; Lents, J.; Osses, M.; Nikkila, N.; Barth, M. Development and application of an international vehicle emissions model. Transp. Res. Rec. J. Transp. Res. Board 2005, 1939, 156-165. [CrossRef]

47. Nagpure, A.S.; Gurjar, B. Development and evaluation of vehicular air pollution inventory model. Atmos. Environ. 2012, 59, 160-169. [CrossRef]

48. Ghadiri, Z.; Rashidi, Y.; Broomandi, P. Evaluation Euro IV of effectiveness in transportation systems of Tehran on air quality: Application of IVE model. Pollution 2017, 3, 639-653.

49. Hongzhao, D.O.; Yongbin, X.U.; Ning, C. A research on the vehicle emission factors of real world driving cycle in Hangzhou city based on IVE model. Automot. Eng. 2011, 33, 1034-1038.

50. ISSRC. IVE Model Users Manual, Version 2; International Sustainable Systems Research Center—ISSRC: La Habra, CA, USA, 2008; Available online: http:/ /issrc.org/ive/downloads/manuals/UsersManual.pdf (accessed on 5 March 2018).

51. Musso, A.; Corazza, M.V.; Tozzi, M. Car sharing in Rome: A case study to support sustainable mobility. Procedia Soc. Behav. Sci. 2012, 48, 3482-3491. [CrossRef]

52. Corazza, M.V.; Musso, A.; Finikopoulos, K.; Sgarra, V. An analysis on health care costs due to accidents involving powered two wheelers to increase road safety. Transp. Res. Procedia 2016, 14, 323-332. [CrossRef]

53. Sgarra, V.; Di Mascio, P.; Corazza, M.V.; Musso, A. An application of ITS devices for powered two-wheelers safety analysis: The Rome case study. Adv. Transp. Stud. 2014, 33, 85-96.

54. Fauser, P.; Thomsen, M.; Pistocchi, A.; Sanderson, H. Using multiple regression in estimating (semi) VOC emissions and con-centrations at the European scale. Atmos. Pollut. Res. 2010, 1, 132-140. [CrossRef] 
55. $\quad$ van de Kassteele, J.; Koelemeijer, R.B.A.; Dekkers, A.L.M.; Schaap, M.; Homan, C.D.; Stein, A. Statistical mapping of PM10 concentrations over Western Europe using secondary information from disper-sion modeling and MODIS satellite observations. Stoch. Environ. Res. Risk Assess. 2006, 21, 183-194. [CrossRef]

56. Xu, H.; Bechle, M.J.; Wang, M.; Szpiro, A.A.; Vedal, S.; Bai, Y.; Marshall, J.D. National PM2.5 and NO2 exposure models for China based on land use regression, satellite measurements, and universal kriging. Sci. Total. Environ. 2019, 655, 423-433. [CrossRef]

57. Jiménez-Palacios, J.L. Understanding and Quantifying Motor Vehicle Emissions with Vehicle Specific Power and TILDAS Remote Sensing. Ph.D. Thesis, Massachusetts Institute of Technology, Department of Mechanical Engineering, Cambridge, MA, USA, February 1999.

58. Zhai, H.; Frey, C.; Nagui, M.A. Vehicle-Specific power approach to speed-and facility-specific emissions estimates for diesel transit buses. Environ. Sci. Technol. 2008, 42, 7985-7991. [CrossRef] [PubMed]

59. Liao, R.; Chen, X.; Yu, L.; Sun, X. Analysis of emission effects related to drivers' compliance rates for cooperative vehicleinfrastructure system at signalized intersections. Int. J. Environ. Res. Public Health 2018, 15, 122. [CrossRef] [PubMed]

60. Onchang, R.; Noisopa, K.; Pawarmart, I. Changes of air pollution and climate forcing emissions due to fuel switching to gasohol in motorcycle fleet in an urban area of Thailand. Environ. Asia 2017, 10, 94-104. [CrossRef]

61. Lai, J.; Yu, L.; Song, G.; Guo, P.; Chen, X. Development of city-specific driving cycles for transit buses based on VSP distributions: Case of Beijing. J. Transp. Eng. 2013, 139, 749-757. [CrossRef]

62. Lozhkina, O.V.; Lozhkin, V.N. Estimation of nitrogen oxides emissions from petrol and diesel passenger cars by means of on-board monitoring: Effect of vehicle speed, vehicle technology, engine type on emission rates. Transp. Res. Part D Transp. Environ. 2016, 47, 251-264. [CrossRef]

63. Seigneur, C. Emissions of Air Pollutants and Emission Control Technologies; Cambridge University Press: Cambridge, UK, 2019.

64. Cooper, B. Sulphate emissions from automobile exhaust. Platin. Met. Rev. 1976, 20, 38-45.

65. El-Baza, F.K.; Gadb, M.S.; Abdoc, S.M.; Abedd, K.A.; Mattere, I.A. Performance and exhaust emissions of a diesel engine burning algal biodiesel blends. Int. J. Mech. Mechatron. Eng. 2016, 16, 151-158.

66. Muhammad, S.; Long, X.; Salman, M. COVID-19 pandemic and environmental pollution: A blessing in disguise? Sci. Total. Environ. 2020, 728, 138820. [CrossRef] [PubMed]

67. Le Quéré, C.; Jackson, R.B.; Jones, M.W.; Smith, A.J.P.; Abernethy, S.; Andrew, R.M.; De Gol, A.J.; Willis, D.R.; Shan, Y.; Canadell, J.G.; et al. Temporary reduction in daily global CO2 emissions during the COVID-19 forced confinement. Nat. Clim. Chang. 2020, 3, 1-8. [CrossRef]

68. Corazza, M.V.; Musso, A. Urban transport policies in the time of pandemic, and after: An arduous research agenda. Transp. Policy 2021, 103, 31-44. [CrossRef]

69. Beyer, R.M.; Manica, A.; Mora, C. Shifts in global bat diversity suggest a possible role of climate change in the emergence of SARS-CoV-1 and SARS-CoV-2. Sci. Total Environ. 2021, 145413. [CrossRef]

70. Sun, Z.; Wang, C.; Ye, Z.; Bi, H. Long short-term memory network-based emission models for conventional and new energy buses. Int. J. Sustain. Transp. 2021, 15, 229-238. [CrossRef] 